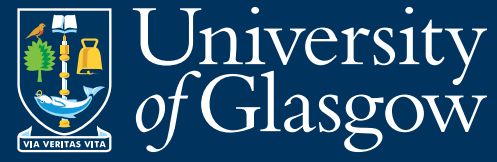

Adam Smith

Business School

WORKING

PAPER

SERIES

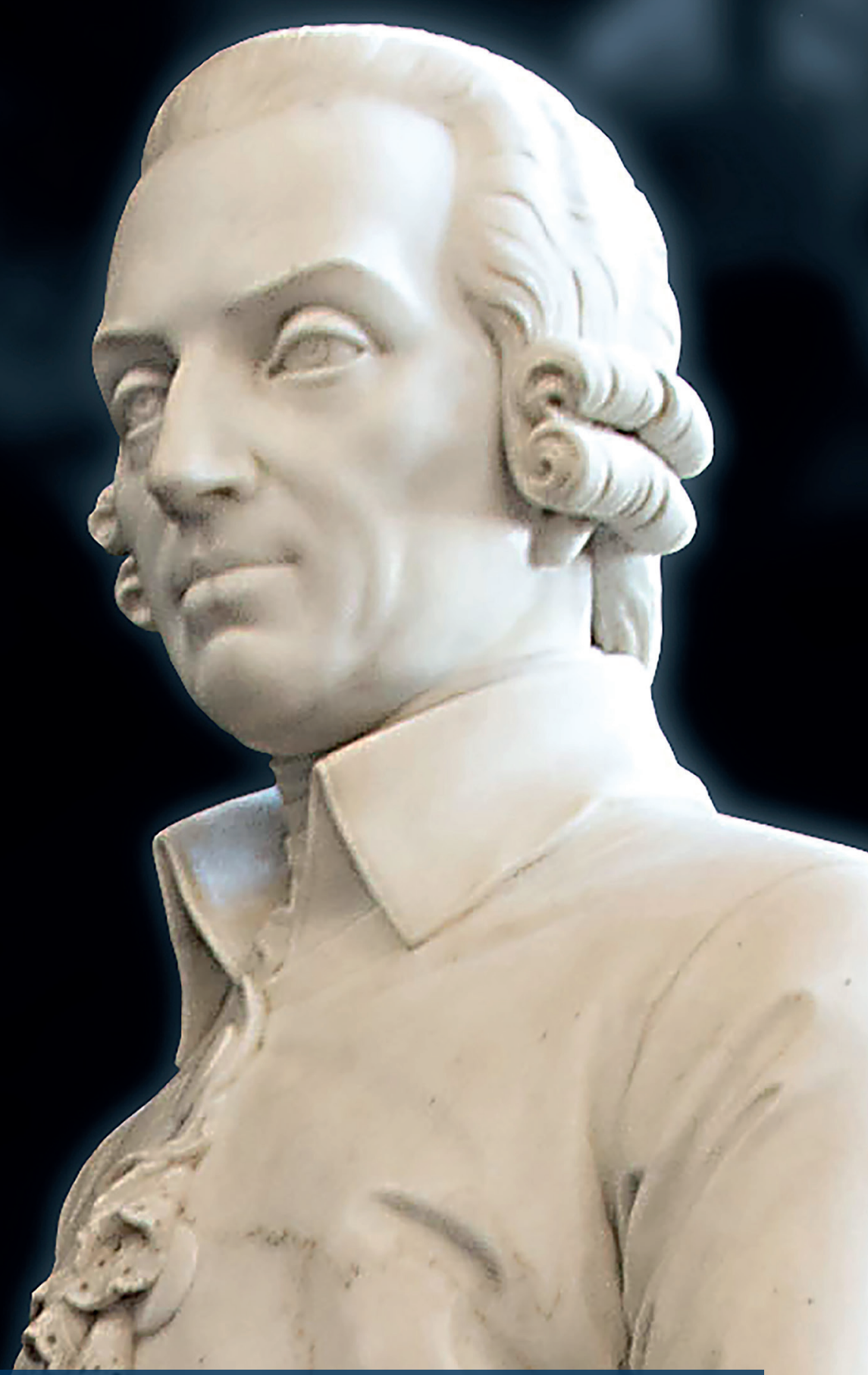

Tight and Loose, and Red and Blue: A 'Dance' of Macro Policies in the US

Tatiana Kirsanova, Celsa Machado and Ana Paula Ribeiro

Paper no. 2020-14

June 2020 


\title{
Tight and Loose, and Red and Blue: A 'Dance' of Macro Policies in the US*
}

\author{
Tatiana Kirsanova ${ }^{\dagger}$ \\ University of Glasgow
}

\author{
Celsa Machado $\ddagger$ \\ Polytechnic of Porto
}

June 4, 2020

\author{
Ana Paula Ribeiro ${ }^{\S}$ \\ University of Porto
}

\begin{abstract}
Using optimising policy framework, we build and estimate a small-scale DSGE model of the US, and tell the story of monetary and fiscal policy interactions in 1955-2018. We find that fiscal policy is important to identify shifts in monetary policy preferences, and it is shaped by the political color. We use this model to analyse the episode of zero lower bound on interest rate in 2008-15. We find that the bound constrained monetary policy, explain some observed irregularities in macroeconomic data, and demonstrate that a change to price level targeting could have generated a powerful lift-off from the constraint.
\end{abstract}

Key Words: Optimal Noncooperative Monetary and Fiscal Policy, Zero Lower Bound, Price Level Targeting, Political Color, Bayesian Estimation with Markov Switching

JEL Reference Number: E31, E52, E62, E63

\footnotetext{
${ }^{*}$ We thank Tatiana Damjanovic, Richard Dennis, Nigar Hashimzade, Stanislav Kolenikov, Junior Maih, Charles Nolan, Kjetil Storesletten and, in particular, Campbell Leith. All errors remain ours. This research was supported by Cef.up with financing from Portuguese public funds through FCT - Fundação para a Ciência e a Tecnologia, I.P., in the framework of the project with references UIDB/04105/2020 and UIDP/04105/2020

${ }^{\dagger}$ Address: Economics, Adam Smith Business School, Guilbert Scott Building, University of Glasgow, Glasgow G12 8QQ; e-mail tatiana.kirsanova@glasgow.ac.uk

${ }^{\ddagger}$ Address: ISCAP-P.PORTO, Rua Jaime Lopes de Amorim, 4465-111 S. Mamede de Infesta, Portugal; email: celsa@iscap.ipp.pt

$\S$ Address: Faculdade de Economia da Universidade do Porto, Gabinete nž 608, Rua Dr. Roberto Frias S/N 4200464 Porto, Portugal; email: aribeiro@fep.up.pt
} 


\section{Introduction}

Responding to the recent financial crisis and the Great Recession, the Fed aggressively cut the short-term interest rate in 2008, kept it at the zero lower bound (ZLB) for seven years, and then, only gradually, raised it to a positive level that nevertheless remained near the historical minimum. This, 'new normal', level of interest rate was too close to the ZLB, leaving little room for monetary policy to react to large and unexpected shocks. The new reality of more frequent ZLB episodes calls for central banks and governments to review their policy frameworks and find potential improvements. ${ }^{1}$

In this paper, we seek to evaluate the current monetary-fiscal policy framework in the United States and suggest some policy changes that may be useful to alleviate the ZLB constraint. A way to achieve these aims is to understand the monetary and fiscal policy 'dance' in the post-war period of the United States. We describe and estimate it in a small-scale DSGE model with Markov switching, which takes into account important policy trade-offs: inflation, output stabilization, and sustainability of public debt. We use optimizing policy framework, which captures noncooperative interactions of monetary and fiscal policies and possible changes in their preferences. Although the strategic monetary and fiscal policy mix is our main interest, we also estimate more conventional and well-studied model describing policy interactions in terms of simple rules. Both models describe recurrent switches of monetary and fiscal policy regimes, including the ZLB regime for monetary policy.

Estimated policy preferences and the policy 'dance' allow us to interpret some of the events of the recent past. The ZLB constraint was relevant for policy decisions, as its absence would have resulted in different dynamics of macroeconomic variables. Inflation, which refused to fall during the ZLB episode despite low demand, could have remained afloat due to uncertainty about the future course of monetary policy, when expectations of hawkish monetary policy and the belief in their ability to raise inflation up to the target played a role. We demonstrate that price level targeting, which has been recently discussed as a potentially improving modification of the current inflation targeting framework, generates a powerful lift-off from the ZLB constraint: its credible announcement results in a sustained increase in the short-term interest rate by 1-2 percentage points within just a quarter.

Throughout history, fiscal policy has been an important partner of monetary policy. Identification of monetary policy objectives is inseparable from identification of fiscal preferences. For

\footnotetext{
${ }^{1}$ For explicit calls for the re-evaluation and, possibly, redesign of monetary policy framework, see Williams (2016), Bernanke (2017), Svensson (2020) to mention only a few.
} 
example, Volcker's monetary policy in the mid-1980s was extremely hawkish as lower taxes under the Reagan administration created additional deflationary pressures, resulting in interest rates becoming excessively high for a low level of monetary inflation conservatism. In their turn, fiscal policy regimes have been shaped by political cycles. Modeling monetary and fiscal interactions as optimal policies reveals a correlation between Republican administrations and fiscal policy which is more consistent with 'long-run growth' motivations. The conventional rule-based model reveals a correlation between Republican administrations and 'fiscal irresponsibility', with little efforts to stabilize debt. Although both models are consistent with historical narratives, the data agree more strongly with optimal policies than with policy rules.

More specifically, the paper considers two distinct descriptions of monetary and fiscal policy interactions, non-cooperative discretionary policy and rule-based policy, and takes into account a potential non-linearity in policy behavior by allowing policies to change either preference or reaction types, which is described by Markov-switching. The optimal policy model estimates policy objectives for each policy maker, assuming microfounded targets for inflation and real variables, but potentially non-microfounded switching weights on these targets. In contrast, a rule-based policy follows most of the literature and switches between active and passive modes in the spirit of Leeper (1991).

The optimal policy model fits the data better than the rule-based model. Inflation-conservative monetary policy dominated in the era of Great Moderation, starting with Volcker disinflation. In modern times, a gradual transition to a more dovish monetary policy occurred before the Great Recession, and the lift-off from the ZLB was executed by doves. Fiscal policy shifts are in good agreement with the narrative and political motivations for legislative tax reforms documented in Romer and Romer (2010). We find that counter-cyclical fiscal policy was more common before the Great Moderation era, identify Republican tax cuts by Reagan and George W. Bush as 'government downsize' or long-run growth driven policy, and uncover the presence of a debt-stabilization component in fiscal policy of the Clinton administration. Fiscal policy had a stronger preference for output stabilization during the 2008 financial crisis, and the fiscal cliff of 2013 shifted preferences towards a less output-conservative regime, where it remained under the Trump administration until the end of 2018, when our data sample ends.

Although the empirical rule-based model does not perform equally well empirically, its historical narrative supports many conventional views; it also provides a sequence of shifts in policy equilibria that correlate with political cycles when the Republican administration is likely to be 'fiscally irresponsible'. Thus, the model suggests the shift to active monetary policy with Vol- 
cker's disinflation, with only a temporary loss in monetary activism in the 2000s, and the lift-off from the ZLB was steered by an active monetary policy before the switch to passive mode under Powell. Fiscal policy has remained active for a long period from the middle of the George W. Bush administration to the present day, with only a temporary improvement in debt stabilization under the Obama administration.

Interpreting recent events, this research contributes to the large literature on the effects of the ZLB. There is a view that the constraint has greatly complicated the Fed's task, see e.g. Kiley and Roberts (2017), Gust et al. (2017), Del Negro et al. (2017). There is also a view that the bound was largely empirically irrelevant, since it did not affect the behavior of economic variables, see e.g. Debortoli et al. (2019). In these arguments, the persistence of positive inflation rates over the whole ZLB period is frequently used as the supporting evidence in assessing the empirical importance of the constraint. Since the standard New Keynesian theory suggests that inflation is likely to fall, either unconventional monetary policy should have led to the constraint stopping to bind, or some additional forces should have intervened and kept inflation stable, see e.g. Cochrane (2017). Using a model similar to ours, but employing different policy design, Bianchi and Melosi (2017) argue that uncertainty about the future monetary and fiscal policy mix and the resulting rate of debt accumulation may have had a substantial positive effect on price expectations of firms. We make two contributions to this discussion. First, we show that the ZLB constraint was relevant for monetary policy, and that the Fed would have preferred to cut the federal funds rate below the bound. Second, we show that reducing uncertainty regarding future discretionary monetary policy alone generates a substantial decrease in inflation, so the persistently positive inflation can be explained by the private sector confidence that the Fed can be tough on inflation and can keep inflation close to the target.

Working with optimal policies, we have an opportunity to evaluate policy proposals that do not go naturally with simple rules and are more consistent with the class of targeting rules, employed by the Fed. We contribute to the large discussion - in the academic literature and among practitioners - on delegation schemes that can potentially improve monetary policy making on the ZLB. Price Level Targeting (PLT) is, perhaps, the most popular delegation scheme as it is consistent with the dual mandate of a typical central bank. Svensson (1999) and Vestin (2006) have demonstrated that a discretionary central banker who targets price level can closely replicate the commitment outcome with higher social welfare. Most research on the PLT was done around the Great Recession, notably by the Bank of Canada, and mainly with the view of reducing the 
probability of hitting the ZLB and more fine-tuned inflation control. ${ }^{2}$ A temporary PLT to be adopted by the Fed, when already on the bound, was proposed by the Chicago Fed President Evans (Evans, 2010). Williams (2016), Bernanke (2019), and Svensson (2020) all suggest that the PLT is a serious alternative to the standard inflation targeting regime, in particular on the ZLB constraint. Using estimated model with endogenous ZLB constraint, this paper contributes to the discussion by providing empirical evaluation of the proposal to implement the PLT while on the constraint. We show that adoption of the PLT results in a powerful lift-off from the ZLB, and this lift-off is not compromised by fiscal policy. The inherent policy uncertainty, and positive probability of reneging on the PLT in the near future, does not compromise this policy proposal either.

Our work contributes to the theoretical and empirical literature on monetary-fiscal policy interactions, see Davig and Leeper (2006), Bianchi and Ilut (2017), and Bianchi and Melosi (2017), to mention the most relevant research. The rule-based policy making discussed in these papers describes how the strength of 'fiscal responsibility', as measured by the willingness to stabilize debt, affects the conduct of monetary policy. Chen et al. (2019) take a step towards modeling policy interactions as targeting rules and non-cooperative policies, however they are mainly concerned with fiscal responsibility, as they restrict fiscal policy objectives to punish deviations from active and passive rules in the sense of Leeper (1991). As a convenient benchmark, we also estimate a rule-based model, contributing to the empirical analysis of the ZLB episode in 2008-15. However, we mainly contribute to the literature by demonstrating that an empirical model of optimal policy, which captures policy preferences and their evolution over time, explains the data very well and results in a different view on macroeconomic policy making in the US than the one that follows from a rule-based model. Unlike most of the literature, fiscal policy uses distortionary taxes as a policy instrument and affects prices directly, in addition to the indirect effect on expected prices working as described by the fiscal theory of the price level.

Finally, this paper is linked to the research on political business cycles. The political and macroeconomic preferences of the ruling party translate into different policies, see Alesina et al. (1997) and Drazen (2000). Similar to Muller et al. (2016) we demonstrate that the color of fiscal responsibility is blue, and confirm that optimal fiscal policy that is more consistent with 'the long-run growth' motivations happened under the red party color.

The paper is organized as follows. Section 2 discusses policy mixes studied in this paper and introduces the jargon. Section 3 presents the setup. It presents model highlights, describes

\footnotetext{
${ }^{2}$ See Bank of Canada (2011) and references within.
} 
policy design, including the detailed discussion of regime switches in both models, it also describes the econometrics strategy. Section 4 presents the results of the Bayesian estimation. Section 5 discusses regime shifts in policy makers' types and presents historical narratives based on each model. Section 6 uncovers political color of fiscal policy shifts. Section 7 reconsiders the Zero Lower Bound episode of 2008-15 and draws lessons from it. Section 8 concludes. Appendix to this paper summarizes empirical results, and there is also Online Appendix containing various details and derivations.

\section{Policy Mix and The Jargon}

This paper discusses the monetary and fiscal policy mix, focusing on short-term stabilization, and using two different models of policy interactions: rule-based and optimal. It is imperative to give a bird-eye view on policy interactions and introduce the jargon from the very beginning of the paper.

Most empirical literature on monetary-fiscal policy interactions and short-term stabilization with Markov switching relevant to this paper describes policy actions in terms of simple nonoptimizing rules in the spirit of Leeper (1991), where the description of a policy rule is highly stylized. Monetary policy either feeds back strongly on inflation, satisfying the Taylor principle, and is classified as active, or otherwise it is passive. In the same vein, a fiscal instrument either feeds back strongly on the debt disequilibrium, so it can be argued that such a rule is likely to be able to return debt to the base regardless of the impact of monetary policy, or it does not feed back on debt at all, and, most likely, there is no fiscal stabilization of debt. The first type of fiscal rule describes a passive fiscal policy, and the second type describes an active fiscal policy. This description of fiscal policy types reminds us the concept of 'fiscal responsibility', although the latter covers many different aspects of fiscal policy (for example, Committee for Responsible Federal Budget, 2008). Following Muller et al. (2016), we take one of its aspects: debt stabilization, which, in high debt periods, can also be described as a "commitment to reduce the deficit'. In this paper, we will use these terms interchangeably, namely, the rule-based model will often be 'the model of fiscal responsibility', and a passive fiscal policy will be a responsible fiscal policy, while an active fiscal policy will be irresponsible.

While the description of rule-based policy is relatively intuitive and well-established, the description of optimal fiscal policy is much less so. ${ }^{3}$ There is also no label convention for the types

\footnotetext{
${ }^{3}$ We are aware of only one relevant paper, Chen et al. (2019), which estimates fiscal preferences in an empirical model of monetary and fiscal policy interactions with Markov switching at business cycle frequency.
} 
of fiscal policy makers. Therefore, the language we use in this paper is inevitably unconventional. Since there is large literature on macroeconomic stabilization, which discusses monetary policy preferences, we will draw an analogy with its language.

Most empirical work on optimal monetary policy agrees that the empirical policy objectives can be captured by microfounded social welfare terms that describe the trade-off between stabilization of inflation and real variables. There is also consensus that over time, monetary policy makers change the degree of inflation conservatism between inflation-conservative and less inflation-conservative types, which are often informally referred to as hawks and doves. ${ }^{4}$

Fiscal policy makers do not express a clear preference for inflation and do not stabilize it. Their publicly-stated motivations for tax changes range from counter-cyclical to philosophical reasons (Romer and Romer, 2010). In this paper, we argue that social welfare terms, which describe empirical fiscal preferences, largely reflect these motivations. Although these terms explicitly describe the trade-off between stabilizing inflation and real variables, they can also reveal the true reasons for changes in tax policy. For example, in a model with distortionary taxes, tax cuts in times of high inflation may signal a preference for stable (lower) inflation, or a preference for stimulating long-run growth, or even a preference for a smaller government size. In turn, a strong preference for output stabilization can describe either a stabilization-driven fiscal policy or certain policy mixes that require stronger debt stabilization through deficit reduction policies. However, since the formal description of fiscal preferences in the model necessarily includes an inflation stabilization term, a Markov-switching model will detect shifts in inflation or output 'conservatism' similar to shifts in monetary preferences towards inflation or output stabilization. To facilitate the exposition, we use the same 'symmetric' approach to policy types as in the rule-based model, and we call the two types of fiscal policy makers inflation-conservative and less inflation-conservative, similar to the classification used for monetary policy makers.

This jargon, inter alia, may describe fiscal preferences for growth-enhancing tax changes, small government size, and stable (low) inflation. Such preferences are frequently attributed to right-wing parties: according to the political business cycle literature, their supporters, mostly with medium-high income, typically advocate against high taxes and inflation, and lesser need for government intervention to achieve higher long-run growth, privileging free markets over government failures (see e.g. Hibbs (1987), Blais et al. (1993), Alesina et al. (1997)). This motivation is 'philosophical' or driven by long-run growth in Romer and Romer (2010), and the

\footnotetext{
${ }^{4}$ For example, Dennis (2006) estimates this form of monetary policy objectives in a non-switching model. Using a Markov-switching model, Chen et al. (2017) estimate the objectives with shifting weights.
} 
term 'fiscal conservatism' is frequently used in the literature to describe it. To recognize the possibility of a broader interpretation of the fiscal inflation conservatism, we also use the term 'conservatism'. In this paper, we will use these terms interchangeably, namely, a fiscal policy maker who is inflation-conservative will be called conservative.

\section{The Model}

\subsection{Model Highlights}

We use a workhorse New Keynesian model modified to take account of the effects of fiscal policy, see, for example, Woodford (2003a). The modeling of the fiscal side follows Woodford (2001) and Leeper and Leith (2016), allowing for variable maturity of government debt.

Specifically, the economy is populated by a continuum of households and firms. Households supply labour to firms, consume and save in the form of government bonds. Firms are monopolistically competitive, and only use labor to produce differentiated tradable goods. There are central bank and the fiscal authority, which act non-cooperatively. The fiscal authority finances spending by long-term bonds and distortionary taxes. The government debt has geometric maturity structure. Full details of underlying microfoundations of the model are given in Online Appendix (OApp) A, and only the linearized model is presented here. Hatted variables indicate that they have been linearized relative to their steady-states. The stationarity of the model's steady state is achieved by scaling by a non-stationary technology process.

The household optimization problem yields the Euler equation and the arbitrage condition

$$
\begin{gathered}
\hat{x}_{t}=\mathbb{E}_{t} \hat{x}_{t+1}-\frac{1}{\sigma}\left(\hat{\imath}_{t}-\mathbb{E}_{t} \hat{\pi}_{t+1}-\mathbb{E}_{t} \hat{z}_{t+1}\right)-\hat{s}_{t}^{\xi}+\mathbb{E}_{t} \hat{s}_{t+1}^{\xi}, \\
\hat{\imath}_{t}=\beta \rho \hat{P}_{t+1}^{M}-\hat{P}_{t}^{M}
\end{gathered}
$$

where $\hat{x}_{t}$ is habits-adjusted consumption

$$
\hat{x}_{t}=(1-\theta)^{-1}\left(\hat{c}_{t}-\theta \hat{c}_{t-1}\right),
$$

and $\hat{c}_{t}$ is consumption with steady state level $c, \hat{\pi}_{t}$ is inflation, $\hat{\imath}_{t}$ is the nominal interest rate, $\hat{P}_{t}^{M}$ is price of long-term bonds and $\hat{s}_{t}^{\xi}$ is a taste shock. Here $\beta<1$ is the household discount rate, $\sigma$ is the inverse of the intertemporal elasticity of substitution, $\varsigma$ is the inverse of the Frisch elasticity, $\theta$ is the habit persistence parameter and parameter $\rho$ regulates maturity of bonds, $m=\frac{1}{1-\beta \rho}$.

The firms' optimization decisions, in presence of both price and inflation inertia, give rise to a hybrid New Keynesian Phillips curve

$$
\hat{\pi}_{t}=\beta \chi_{f} \mathbb{E}_{t} \hat{\pi}_{t+1}+\chi_{b} \hat{\pi}_{t-1}+\kappa_{c}\left(\sigma \hat{x}_{t}+\varsigma \hat{y}_{t}+\frac{\tau}{1-\tau} \hat{\tau}_{t}\right)+\hat{s}_{t}^{\mu}
$$


where $\hat{y}_{t}$ denotes output with steady state level $y, \hat{\tau}_{t}$ is the labor income tax rate with the steady state level $\tau$, and $\hat{s}_{t}^{\mu}$ is a cost-push shock. The reduced form parameters are $\chi_{f}=\alpha / \Phi, \chi_{b}=\zeta / \Phi$, $\kappa_{c}=(1-\alpha)(1-\zeta)(1-\alpha \beta) / \Phi$, with $\Phi=\alpha(1+\beta \zeta)+(1-\alpha) \zeta, 1-\alpha$ is the Calvo (1983) probability of price change, and $\zeta$ is the proportion of firms setting prices who follow a backward-looking rule of thumb, rather than setting prices optimally. ${ }^{5}$

There is also an aggregate resource constraint and the government budget constraint

$$
\begin{gathered}
\hat{y}_{t}=\frac{c}{y} \hat{c}_{t}+\frac{g}{y} \hat{g}_{t} \\
\tilde{b}_{t}=\frac{1}{\beta} \tilde{b}_{t-1}+\frac{1}{\beta} \frac{b}{y}\left(\beta(\rho-1) \hat{P}_{t}^{M}-\hat{\pi}_{t}-\hat{s}_{t}^{z}\right)+\frac{g}{y} \hat{g}_{t}-\tau\left(\hat{\tau}_{t}+\hat{y}_{t}\right)+\hat{s}_{t}^{\nu}
\end{gathered}
$$

where $\tilde{b}_{t}$ is normalized real debt with steady state level $b, \hat{g}_{t}$ is government spending with steady state level $g, \hat{s}_{t}^{\nu}$ is a term premium shock and $\hat{s}_{t}^{z}$ is a stationary technology shock.

The technology, cost-push, preference, government spending and term premium shocks follow $\operatorname{AR}(1)$ processes:

$$
\hat{s}_{t}^{j}=\rho^{j} \hat{s}_{t-1}^{j}+\sigma_{j} \varepsilon_{t}^{j}, \quad \varepsilon_{t}^{j} \sim N(0,1)
$$

where $j \in\{\xi, z, \mu, g, \nu\}$.

Policy instruments are the short term interest rate $\hat{\imath}_{t}$ and tax rate $\hat{\tau}_{t}$. We close the model with policy as discussed next.

\subsection{Policy}

Policy interactions can take one of two different forms: either simple rules or optimal discretionary policy, as we describe in this section. Both optimal and rule-based models allow for Markov switching between different policy regimes (or modes), as the conduct of macroeconomic policy have changed over time. In particular, there has been an important shift in the behavior of monetary policy, with the ZLB constraint on short term interest rates during the recent financial crisis. To identify this shift we follow Bianchi and Melosi (2017) and introduce two distinct policy regimes: zero-low-bound regime $Z$ and normal regime $N$. The switches of the economy between these two regimes are governed by two-regime Markov chain $v_{Z} \in\{N, Z\}$ with transition matrix

$$
T^{Z}=\left[\begin{array}{cc}
d_{n n} & 1-d_{n n} \\
1-d_{z z} & d_{z z}
\end{array}\right]
$$

where $d_{i j}=P\left(v_{Z, t+1}=j \mid v_{Z, t}=i\right)$. There are policy and shock volatility shifts in $N$-regime, but they are best discussed together with policy specifications.

\footnotetext{
${ }^{5}$ All parameters in this Phillips curve are assumed to be structural, see Galí and Gertler (1999).
} 


\subsubsection{Optimal Discretionary Policy and Regime Shifts}

We assume that the empirical objective function of the Fed takes a microfounded form. Specifically, the empirical loss function, taking into account the possibility of a zero low bound regime, can be written as

$$
\begin{aligned}
L^{M} & =\mathbb{I}_{N} \mathbb{E}_{0} \sum_{t=0}^{\infty} \beta^{t}\left(\omega_{\pi}^{M}\left(\varsigma_{M}\right)\left(\hat{\pi}_{t}^{2}+\frac{\zeta}{\alpha(1-\zeta)}\left(\Delta \hat{\pi}_{t}\right)^{2}\right)+\omega_{x}\left(\hat{x}_{t}+\hat{s}_{t}^{\xi}\right)^{2}\right. \\
& \left.+\omega_{y}^{M}\left(\hat{y}_{t}-\frac{\sigma}{\varphi} \hat{s}_{t}^{\xi}\right)^{2}+\omega_{i}\left(\Delta \hat{\imath}_{t}\right)^{2}\right)+\mathbb{I}_{Z} \mathbb{E}_{0} \sum_{t=0}^{\infty} \beta^{t}\left(\hat{\imath}_{t}-\hat{\imath}_{t}^{Z}\right)^{2} .
\end{aligned}
$$

Here $\mathbb{I}_{Z}$ is an indicator function, equal to one if there is zero low bound for interest rate and zero otherwise, and $\mathbb{I}_{N}=1-\mathbb{I}_{Z}$. In regime $N\left(\mathbb{I}_{N}=1\right)$, the Fed determines the relative importance of welfare-relevant terms and chooses the short term interest rate $\hat{\imath}_{t}$ to minimize the loss, while in regime $Z$ it cannot move the interest rate below the bound $\hat{\imath}_{t}^{Z}$ and it is not optimal to raise it above this bound. The last quadratic term in function (8) captures this behavior.

In regime $N$ the policy objective takes a microfounded form (see OApp B for the microfoundations), although coefficients on the quadratic terms are estimated freely. This objective captures the standard trade-off between stabilization of inflation and real gap terms. The two real gap terms in policy objectives imply that in times of high $\hat{\xi}_{t}$ and therefore low utility of consumption and low disutility of labour, a benevolent policy maker should encourage more work and delay consumption until better times. The relative weights $\omega$ may change over time to describe the non-linearity of preferences over a long historical period and the associated policy uncertainty in the conduct of monetary policy. ${ }^{6}$

The relative weight on inflation terms stabilization, $\omega_{\pi}$, shifts between one and a value lower than one to describe two policy regimes with different inflation conservatism. An inflationconservative regime is labeled $C$, and a less inflation-conservative regime is labeled $L$. Note that the difference in conservatism is determined endogenously, and therefore the loss of conservatism in the $L$-regime relative to the $C$-regime is only relative, and not absolute. The shifts between regimes $C$ and $L$, which only occur in the normal regime $N$, are regulated by two-regime Markov chain $\varsigma_{M} \in\{C, L\}$ with probabilities $p_{i j}=P\left(\varsigma_{M, t+1}=j \mid \varsigma_{M, t}=i\right)$ and transition matrix

$$
T^{M}=\left[\begin{array}{cc}
p_{c c} & 1-p_{c c} \\
1-p_{l l} & p_{l l}
\end{array}\right]
$$

\footnotetext{
${ }^{6}$ This objective was also used in a pure monetary model by Chen et al. (2017).
} 
We assume that empirical fiscal policy objectives are similarly microfounded:

$$
\begin{aligned}
L^{F} & =\mathbb{E}_{0} \sum_{t=0}^{\infty} \beta^{t}\left(\omega_{\pi}^{F}\left(\varsigma_{F}\right)\left(\hat{\pi}_{t}^{2}+\frac{\zeta}{\alpha(1-\zeta)}\left(\Delta \hat{\pi}_{t}\right)^{2}\right)+\omega_{x}\left(\hat{x}_{t}+\hat{s}_{t}^{\xi}\right)^{2}\right. \\
& \left.+\omega_{y}^{F}\left(\varsigma_{F}\right)\left(\hat{y}_{t}-\frac{\sigma}{\varphi} \hat{s}_{t}^{\xi}\right)^{2}+\omega_{\tau}\left(\Delta \tilde{\tau}_{t}\right)^{2}\right) .
\end{aligned}
$$

We normalize the coefficient on habit-adjusted consumption term, $\omega_{x}$, to be the same as in the monetary objective, and allow weights on output gap $\omega_{y}^{F}$ and inflation $\omega_{\pi}^{F}$ to shift between two regimes. These shifts are controlled by two-regime Markov chain $\varsigma_{F} \in\{C, L\}$, where an inflation-conservative fiscal policy maker ( $C$-regime) is described by a higher $\frac{\omega_{\pi}^{F}}{\omega_{y}^{F}}$ ratio than a less inflation-conservative one ( $L$-regime). The shifts are described by transition matrix

$$
T^{F}=\left[\begin{array}{cc}
q_{l l} & 1-q_{l l} \\
1-q_{c c} & q_{c c}
\end{array}\right],
$$

with $q_{i j}=P\left(\varsigma_{F, t+1}=j \mid \varsigma_{F, t}=i\right)$. The weight on the fiscal instrument smoothing term is assumed to be the same for both regimes.

The literature on good luck or good policy demonstrates that shock volatilities change with time and play an important role in explaining the US inflation dynamics, see e.g. Sims and Zha (2006). We, therefore, assume that in the normal regime their shifts are governed by two-regime Markov chain $\varsigma_{S} \in\{T, V\}$, where regime $T$ describes relatively low volatility of all five shocks ('tranquil' regime) and regime $V$ describes relatively high volatility of them ('volatile' regime). Transition is described by $s_{i j}=P\left(\varsigma_{S, t+1}=j \mid \varsigma_{S, t}=i\right)$ and by matrix

$$
T^{S}=\left[\begin{array}{cc}
s_{t t} & 1-s_{t t} \\
1-s_{v v} & s_{v v}
\end{array}\right]
$$

The joint process for monetary and volatility shifts is given by the transition equation

$$
\left[\begin{array}{lllll}
P_{C V} & P_{L V} & P_{C T} & P_{L T} & P_{Z}
\end{array}\right]_{t+1}=\left[\begin{array}{lllll}
P_{C V} & P_{L V} & P_{C T} & P_{L T} & P_{Z}
\end{array}\right]_{t} T^{S M}
$$

with transition matrix

$$
T^{S M}=\left[\begin{array}{ccc}
d_{n n} T^{M} s_{v v} & d_{n n} T^{M}\left(1-s_{v v}\right) & \left(1-d_{n n}\right)\left[\begin{array}{l}
1 \\
1
\end{array}\right] \\
d_{n n} T^{M}\left(1-s_{t t}\right) & d_{n n} T^{M} s_{t t} & \left(1-d_{n n}\right)\left[\begin{array}{l}
1 \\
1
\end{array}\right] \\
\left(1-d_{z z}\right)\left[\begin{array}{cc}
p_{c z} & 1-p_{c z}
\end{array}\right] s_{v z} & \left(1-d_{z z}\right)\left[\begin{array}{cc}
p_{c z} & 1-p_{c z}
\end{array}\right]\left(1-s_{v z}\right) & d_{z z}
\end{array}\right],
$$

where $s_{v z}$ is the probability of the transition from the high volatility normal regime to the zero low bound regime, and $p_{c z}$ is the probability to move from an inflation-conservative and also normal monetary regime to the zero low bound regime. 
Finally, transition between ten monetary-fiscal-volatility regimes is described by a transition matrix which is a Kronecker product of $T^{S M}$ and $T^{F}$.

When implementing non-cooperative discretionary policy, monetary and fiscal policy makers move simultaneously. They select policy instruments to minimize the relevant loss function, (8) or (9), subject to the structural equations describing private sector behavior, equations (1)-(6) and the evolution of shocks.

The solution procedure for Markov-switching non-cooperative policy interactions is based on Svensson and Williams (2007) and adjusted for two non-cooperative authorities following Currie and Levine (1993) and e.g. Blake and Kirsanova (2011). ${ }^{7}$

\subsubsection{Simple Rules and Regime Shifts}

The rule-based model of monetary-fiscal policy interactions is based on Davig and Leeper (2006), Bianchi and Melosi (2017) and Bianchi and Ilut (2017), with monetary and fiscal rules describing active and passive policy in spirit of Leeper (1991). Specifically, monetary policy instrument rule is a generalized Taylor rule which is specified as

$$
\hat{\imath}_{t}=\mathbb{I}_{N}\left(\rho^{M}\left(\varkappa_{M}\right) \hat{\imath}_{t-1}+\left(1-\rho^{M}\left(\varkappa_{M}\right)\right)\left[\psi_{\pi}\left(\varkappa_{M}\right) \hat{\pi}_{t}+\psi_{y}\left(\varkappa_{M}\right)\left(\Delta \hat{y}_{t}+\hat{s}_{t}^{z}\right)\right]+\hat{\varepsilon}_{t}^{M}\right)+\mathbb{I}_{Z} \hat{\imath}_{t}^{Z} .
$$

In regime $N$, the Fed adjusts the short term interest rate in response to changes in inflation and deviations in output growth from the trend. ${ }^{8}$ Parameters $\left(\rho^{M}, \psi_{\pi}, \psi_{y}\right)$ shift with monetary policy regime $\varkappa_{M} \in\{A, P\}$, where regime $A$ describes active monetary policy with strong feedback on inflation, regime $P$ describes passive monetary policy which accommodates inflation. We add an i.i.d. monetary policy shock $\hat{\varepsilon}_{t}^{M}$. In regime $Z$, interest rate is on the bound $\hat{\imath}_{t}^{Z}$.

We estimate fiscal rule in the form

$$
\tilde{\tau}_{t}=\rho^{F}\left(\varkappa_{F}\right) \tilde{\tau}_{t-1}+\left(1-\rho^{F}\left(\varkappa_{F}\right)\right)\left(\delta_{b}\left(\varkappa_{F}\right) \tilde{b}_{t-1}+\delta_{y} \hat{y}_{t}\right)+\hat{\varepsilon}_{t}^{F} .
$$

Here rule parameters $\left(\rho^{F}, \delta_{b}\right)$ depend on fiscal policy regime $\varkappa_{F} \in\{P, A\}$, where regime $P$ describes passive fiscal policy which evidently responds to the debt level with $\delta_{b}(P)>0$, and regime $A$ describes active fiscal policy with zero feedback on debt, $\delta_{b}(A) \equiv 0$. Feedback on output, $\delta_{y}$, is assumed to be the same for both fiscal regimes. We add an i.i.d. fiscal policy shock $\hat{\varepsilon}_{t}^{F}$.

As in the case of optimal policy, we assume that in regime $N$ the shock volatility may change with time. Such shifts are controlled by two-state Markov chain $\varkappa_{S} \in\{T, V\}$ where regime

\footnotetext{
${ }^{7}$ The details of the solution algorithm are provided in OApp D.

${ }^{8}$ Rules of this form have been frequently estimated, see An and Schorfheide (2007), Schorfheide (2005), Chen et al. (2017).
} 
$T$ describes low volatility of all five shocks, regime $V$ describes high volatility of them. As the structure of Markov switches is identical to the one for optimal policy, transition matrices are constructed in the same way as described above, and they are reported in OApp C. The equilibrium dynamics then can be solved by using any available methods, i.e. Svensson and Williams (2007) and Farmer et al. (2011).

\subsection{Estimation Strategy}

The empirical analysis uses US data on output growth, inflation, nominal interest rates, debt to GDP ratio and federal tax revenue ratio from 1955Q2 up to 2018Q4 (255 observation points), which includes the period of ZLB. The dataset, data transformations, and the standard estimation strategy are described in OApp E.

We keep a number of parameters fixed, as some of them are related to steady state values and could not be estimated from a log-linearized demeaned model. We calibrate the discount factor, $\beta$, to be 0.99 , which implies an annual steady state real interest rate of about $4 \%$. The steady state tax rate is set to 0.35 , the steady state government share is set to 0.2 and the steady state debt to GDP ratio is set to 0.35 , as the US data suggest.

The priors are reported in Table A1 in Appendix to this paper. To set priors for the structural parameters of the model, we follow Smets and Wouters (2003), and, in particular, Chen et al. (2017), Bianchi and Melosi (2017) and Bianchi and Ilut (2017), who estimate equally stylized models. Most priors are relatively loose, parameters with support $[0,1]$ are described by a wide beta distribution with a standard deviation of 0.15 , priors for standard deviations of shock variables are described by a very wide inverse gamma distribution. We also use the normal distribution for several parameters that can exceed one, notably for the inverse of intertemporal elasticity of substitution $\sigma$, the inverse Frisch elasticity $\varphi$, and the long-run rule parameters $\psi$ and $\delta$. The only relatively narrow prior describes the Calvo parameter $\alpha$, but the standard deviation of this prior allows the average length of fixed-price contracts to vary more three to five quarters, which is consistent with most studies.

Finally, based on Komunjer and Ng (2011) identification test, all model parameters are identifiable, see OApp F.

\section{Estimation Results}

Table A1 contains the estimation results. We present it in the Appendix to this paper, and also summarize the main findings in this section. From the very beginning, it is important to note 
that the rule-based empirical model is standard and gives estimates of parameters and shocks that are extremely close to those presented in the existing monetary-fiscal rule-based studies, first of all in recent Bianchi and Melosi (2017) and Bianchi and Ilut (2017), but also in earlier Davig and Leeper (2006). It is interesting and important, therefore, to compare the estimates for the new empirical model of optimal policy with the estimates for the benchmark rule-based model.

\subsection{Structural Parameters and Shocks}

Estimates of structural parameters are generally consistent with other studies: the intertemporal elasticity of substitution $\sigma$ is about 3; the inverse Frisch elasticity $\varphi$ is about 2. A measure of price stickiness, $\alpha$, implies that price contracts last for one year on average.

Consistently with other studies which compare discretion and rules (e.g., Chen et al., 2017), there is a difference between inflation indexation estimates: rule-based policy gives higher values than optimal policy. If there were substantial inertia in price indexation, optimal policy rates under discretion would have to react aggressively to cost push shocks. The resulting instrument volatility would not match the data well and would require smoothing of the instrument. We do introduce smoothing objectives for both policies to control for such case, but the data agree better with relatively small weights on these objectives and low inflation inertia.

Estimates of shock processes are similar for optimal policy and rules, although taste and cost-push shocks under discretion are slightly more persistent. There is a statistically significant difference between shock volatilities in $\mathrm{V}$ and $\mathrm{T}$ regimes, while shock volatilities on the ZLB are as high as in V-regime for all shocks except the cost-push shock. The volatility of cost push shocks on the ZLB is relatively small.

\subsection{Policy Parameters}

\subsubsection{Rules-based policy}

Table 1 compares policy parameters for different rule-based policy regimes. Estimates of the rules coefficients are consistent with Leeper (1991) description of monetary and fiscal policies as active and passive. The numerical values of the parameters in all four specifications of the rules are in complete agreement with most studies of monetary-fiscal interactions in DSGE models, in particular, Davig and Leeper (2006), Bianchi and Melosi (2017) and Bianchi and Ilut (2017), despite different empirical methods used in these papers. We find a very clear dichotomy between the two monetary policy regimes: the average feedback on inflation, $\psi_{\pi}$, switches between 2.6 and 0.5 with no overlap in confidence intervals across the two regimes; the persistence coefficient 
Table 1: Policy Coefficients, Rule-based Policy

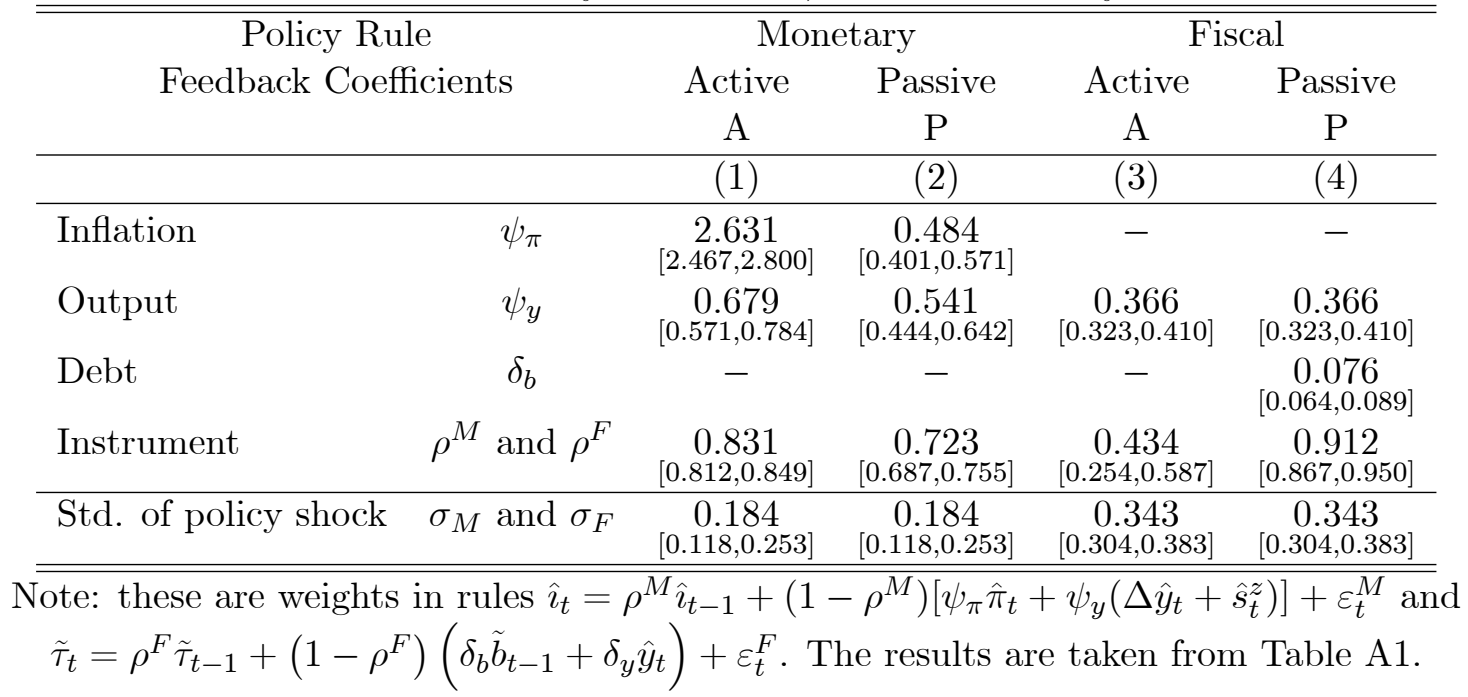

of the monetary policy rule, $\rho^{R}$, in the passive mode is significantly smaller than in the active mode. The feedback on output is similar in both monetary regimes.

The feedback on debt in the passive fiscal rule satisfies $\delta_{b}>\frac{1}{\beta}-1$. The feedback on output, $\delta_{y}$, is estimated at about 0.37 and is statistically similar to the corresponding estimates of $0.28-0.35$ in Bianchi and Melosi (2017) and Bianchi and Ilut (2017). Like them, we also find that a passive fiscal rule is significantly more persistent than an active rule. The presence of a sizeable feedback on output and smaller persistence of the active fiscal rule make fiscal policy to react stronger and sooner to a change in economic conditions, even if a direct response to debt is prohibited. A higher tax rate in times of booms may help to stabilize debt.

\subsubsection{Optimal policy}

Table 2 presents the estimated policy weights, which are normalized in such a way that the weight on the inflation stabilization target in both policy objectives is equal to one. These estimates show that the marginal data density is maximized when both monetary regimes have substantial relative weight attached to the inflation stabilization target. Although the normalized weight on the output gap term, $\varpi_{y}$, doubles when switching from conservative to less-conservative regime, monetary policy remains more inflation-conservative than estimated in Chen et al. (2017). Consistently with the low indexation of prices, the empirical weight on the interest rate smoothing target is relatively small. Note that the weight on the consumption gap term in the more conservative regime is similar to the theoretical weight, derived from the estimated structural parameters 
Table 2: Normalized Policy Weights, Optimal Policy

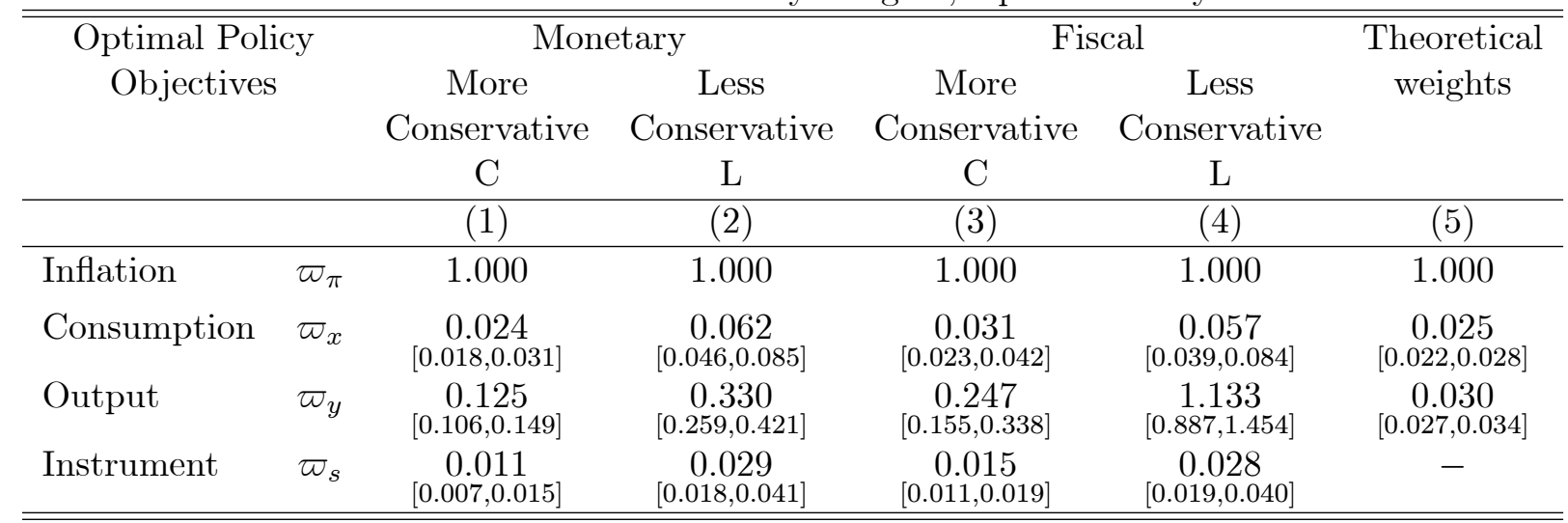

Note: these are weights in the flow objective function

$L=\varpi_{\pi}\left(\hat{\pi}_{t}^{2}+\frac{\zeta}{\alpha(1-\zeta)}\left(\Delta \hat{\pi}_{t}\right)^{2}\right)+\varpi_{x}\left(\hat{x}_{t}+\hat{s}_{t}^{\xi}\right)^{2}+\varpi_{y}\left(\hat{y}_{t}-\frac{\sigma}{\varphi} \hat{s}_{t}^{\xi}\right)^{2}+\varpi_{s}\left(\Delta \text { inst }_{t}\right)^{2}$ where inst $_{t}=$

$\Delta \hat{\imath}_{t}$ in monetary policy objective and $i_{n s t}=\Delta \tilde{\tau}_{t}$ in fiscal policy objective. The results are based on estimates in Table A1.

of the model.

Estimated fiscal policy weights suggest that fiscal policy makers put more weight on output stabilization terms than their monetary peers. A comparison of columns (2) and (3) suggests that these preferences are similar, as $90 \%$ confidence intervals for the output weight overlap. As we discuss later, at no time point a more inflation-conservative government appoints a central banker with strictly less inflation-conservatism than their own. For both fiscal types, the weight on the instrument smoothing term is relatively small.

\section{Tight and Loose}

Estimated parameters allow us to identify the policy maker's type in each time point. As we shall see, regime switches in monetary policy are naturally structured into 'three eras organized around some well-known "Greats". The first era comprises the postwar years through the Great Inflation. The second era brought the Great Moderation but ended in the Great Recession. The third era is still under way, and time will tell what "Greats" may emerge'. ${ }^{9}$ However, more detailed narratives are different for the rule-based and optimal policies. Although the description of monetary policy in both models look the same - both monetary policy makers stabilize inflation and a measure of the output gap - patterns of monetary shifts may look different because they may capture different degrees of inflation conservatism, and because they are partly determined

\footnotetext{
${ }^{9}$ Quotation from Powell (2019).
} 
by fiscal policy decisions.

The account of fiscal policy changes in the two approaches is certainly different. An explicit response to debt in the rule-based model is an attribute of a particular type of the fiscal policy maker that reflects its 'responsibility', see e.g. Muller et al. (2016). In contrast, optimal fiscal policy does not have an explicit goal of debt stabilization, but its preferences change in accordance with fiscal 'conservatism', which may reflect policy changes driven by debt or deficit stabilization motives, by short-run stabilization, or by preferences for long-run growth, as discussed in Romer and Romer (2010).

Because we estimate policy changes directly in a DSGE model, without combining regimes into monetary and fiscally led, we find more regime switches in the rule-based model than Bianchi and Melosi (2017), and even Davig and Leeper (2006) who use different estimation approach. We also use a longer sample than the latter paper, which allows better identification of policy switches, in particular for fiscal policy. We, therefore, provide a detailed description of the policy changes that we identify.

\subsection{The Rule-Based Model}

Figure 1 presents the smoothed probabilities of regime switches. Panel A reports results for monetary policy. Zero lower bound, or Z-regime, is identified to occur between 2009Q1 and 2015Q4 and has the lightest color. The normal N-regime is identified with virtually $100 \%$ probability in all other times, and it is a mixture of either active $(\mathrm{A})$ or passive $(\mathrm{P})$ monetary regimes.

Specifically, in N-regime, two lines separate dark, shaded, and light color areas. ${ }^{10}$ The dark area shows the least probability of the Fed being passive, which is identified with $95 \%$ confidence. The light area shows the least probability of the Fed being active, which is identified with $95 \%$ confidence. The shaded area in between is the area of high uncertainty in the regime classification. For example, monetary policy in 2007Q1 was at least $41 \%$ passive and at least $25 \%$ active with $95 \%$ confidence, so there is large uncertainty about the type of monetary regime in this quarter. However, monetary policy in 2001Q4 was at least 95\% active, and at least 99\% passive in 2018Q3 - both identified with $95 \%$ confidence - leaving little room for the policy type uncertainty in any of these quarters. Displaying these distribution properties helps us identify periods with very strong signals about the type of policy regime. In what follows, we refer to these least probabilities as the probabilities of being in a certain regime. The regime switches in Panels B and C should be

\footnotetext{
${ }^{10}$ These two lines are two $5 \%$ top and bottom quantiles of the $p$-distribution when we de-facto have two regimes, and $p$ is the probability of being in one of them.
} 
interpreted in the same way.

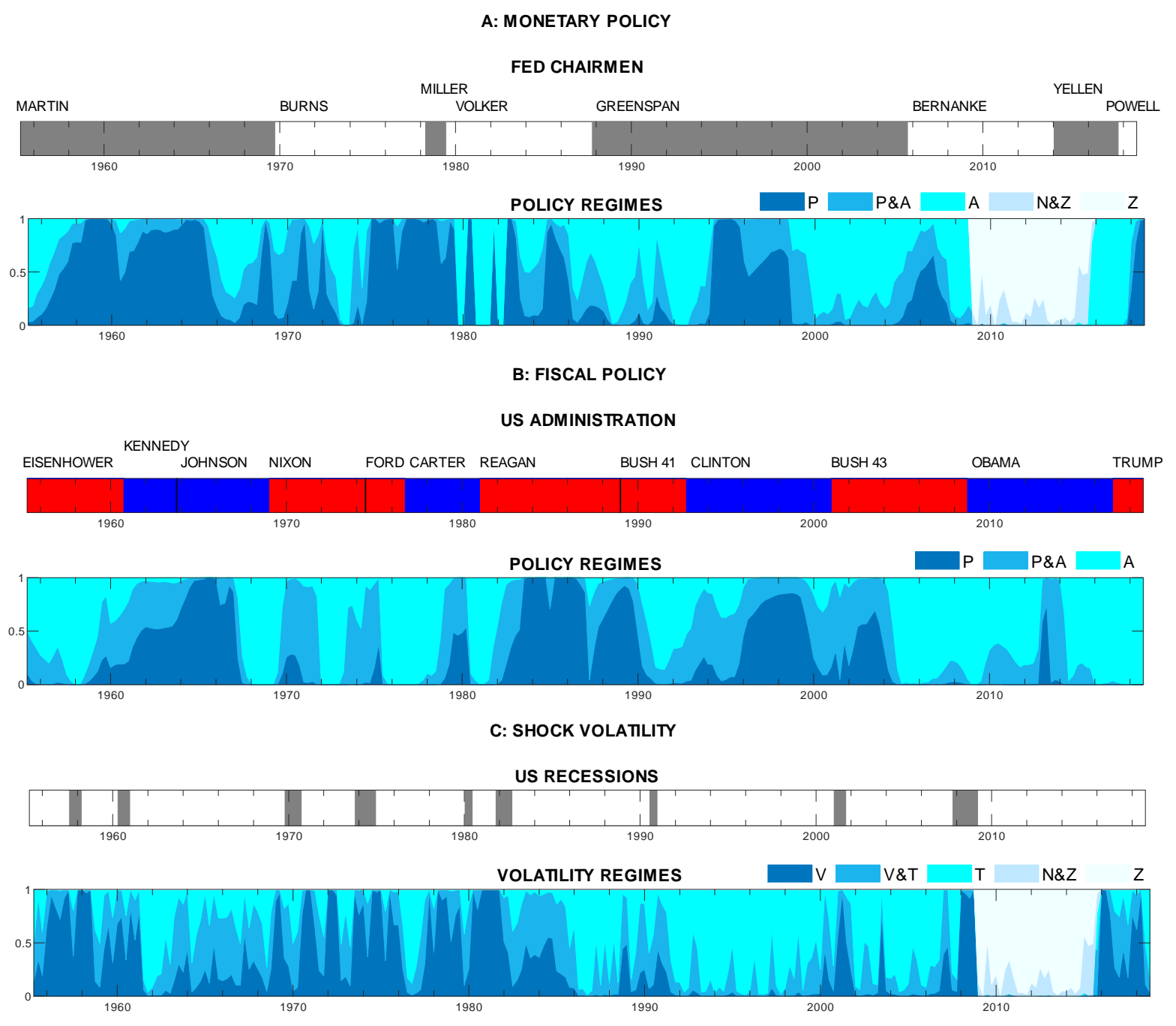

Figure 1: Regime switches, Rule-based policy

Regime switches in monetary policy indicate that the change from a largely passive monetary policy during the Great Inflation period to the Great Moderation with a dominant active monetary policy took place in the early 1980s, and at the same time a largely active fiscal policy in pre-1980s switches to become largely passive. This substantial shift in both policies is generally consistent with findings in Davig and Leeper (2006), Bianchi and Melosi (2017) and Bianchi and Ilut (2017), while monetary shifts alone are also consistent with the findings of other observers who only study monetary policy. We find a long period of active monetary and active fiscal policy, which begins 
in mid-2000 and lasts until 2018 - with the exception of the ZLB period - when the rapid build-up of public debt occurs in times of low and stable inflation. ${ }^{11}$

A more detailed account of these switches is in good agreement with the history of macroeconomic policy in the US. Notably, regime switches are very frequent, but there is good cohesion with frequent changes in actual policies.

In 1951 Martin became the first Chairman of the Independent Fed. In 1956 - at the beginning of our data sample and where the monetary policy is tight - he described the Fed's goal as 'leaning against the winds of deflation or inflation, whichever way they are blowing'. ${ }^{12}$ Despite the known anti-inflation stance and the history of active 'modern monetary policy' in the 1950s (Romer and Romer, 2002), Martin's monetary policy turns into a well-defined passive mode around 1958.

The fiscal narrative starts with the period around 1957 recession, that led to a decrease in the effective tax rate. This reduction and the subsequent increase in debt are more in line with the active fiscal policy regime, which pays little attention to debt accumulation. The increase in government spending on social security led to several tax increases in 1961-62 (Romer and Romer, 2010). The absence of fiscal feedback on spending in our empirical fiscal rule reflects this behavior with increased feedback on debt and yields the passive mode for fiscal policy.

Monetary policy remained largely passive until 1965 when the Great Inflation came along. Fighting high inflation, the Fed raised the discount rate several times - notably in 1966 - which is identified as a return to an active monetary policy. The Revenue and Expenditure Control Act of $1968^{13}$ is identified by our model as a switch to an active fiscal policy, since previous efforts to control the debt-to-output ratio brought it below its data-implied steady state.

The cost-push effect of higher taxes, together with a lower interest rate in 1968, returns monetary policy to a passive mode, but only temporarily. Inflation accelerated, and the first serious attempt to combat the Great Inflation took place in $1969 .{ }^{14}$ An implied interest rate increase shifts monetary policy away from the passive mode.

Chairman Burns succeeded Martin in 1970. The second attempt to disinflate by reducing the M1 growth rates is generally attributed to 1973-74, which is the period of an oil price shock and a surge in inflation. Wage and price controls, introduced in 1971, remained in effect until 1974,

\footnotetext{
${ }^{11}$ Most of the literature has shorter data samples to detect this switch. Note that although such a regime can be explosive, it does not present a problem for the stability of the overall model, which remains mean-square stable in the sense of e.g. do Valle Costa et al. (2005). Future switches away from this regime affect expectations and stabilize the dynamics of the economy.

${ }^{12}$ The chronicle of the Fed's history at https://www.federalreservehistory.org/people/william_mcchesney_martin_jr

${ }^{13}$ One of the largest countercyclical tax change, according to Romer and Romer (2010).

${ }^{14}$ See https://www.federalreservehistory.org/essays/treas_fed_accord_to_mid1960s
} 
arguably contributing to the effect on inflation in line with the active monetary policy regime. The fiscal policy under the Nixon-Ford administration remained largely active, with relatively stable and low debt levels, with the exception of the short period of oil price shocks in 197374, when fiscal policy raised taxes and mitigated the debt consequences of high interest rates. Monetary policy shifted into passive mode at the end of 1974. It remained passive for the next 5 years until Volcker was appointed in 1979. Fiscal policy shifted to the active mode with the Tax Reduction Act of 1975.

There are frequent but well-defined switches in monetary policy mode in 1979-82, they can be attributed to the period of Volcker's policy of managing bank reserves and the resulting volatility of market rates. ${ }^{15}$ The Carter tax cut of 1979 started the period of active fiscal policy which was further supported by the Reagan's Economic Recovery Tax Act of 1981, see also Davig and Leeper (2006). Tax Equity and Fiscal Responsibility Act of 1982 and the Deficit Reduction Act of 1984, which aimed to raise revenues in response to the rapidly increasing debt-output ratio, returned fiscal policy to the passive mode.

The long period of 1983-90 is identified as an overall passive fiscal policy, while monetary policy gradually evolves towards being active with several short-term and largely uncertain switches into the passive mode. Reagan reappointed Volcker and then appointed Greenspan in 1987. At the end of the Bush term in the office in 1990-91, with a large budget deficit and fast build-up of the government debt, fiscal policy gradually shifts into the active mode.

Clinton inherited a large budget deficit and promised deficit reduction via higher taxes. Omnibus Budget Reconciliation Act of 1993 reduced taxes for poor, increased taxes for the wealthy, and introduced rules to keep the budget balanced. As a result, the effective tax rate has been steadily increasing throughout the entire Clinton administration. The model identifies the fiscal policy regime as extremely uncertain in the mid-1990s, with a slightly higher probability of an active mode, and with a switch to a passive mode by around 1997 .

Monetary policy remained largely active under Greenspan, with one well-defined exception in 1994-98, when interest rate hikes ${ }^{16}$ in times of falling inflation and slowing growth shifted monetary policy into passive mode for some time. The first decade of the new millennium was marked by only a slight decrease in the degree of monetary activism during the period of assetprice-driven inflation in 2005-06, when Bernanke became the new Chairman of the Fed. Tight monetary policy in the 2000s coexisted with a largely active fiscal policy: with Bush's term

\footnotetext{
${ }^{15}$ See https://www.federalreservehistory.org/essays/anti_inflation_measures.

${ }^{16}$ Goodfriend (2002) discusses that the Fed made a preemptive move against an expected rise in future inflation.
} 


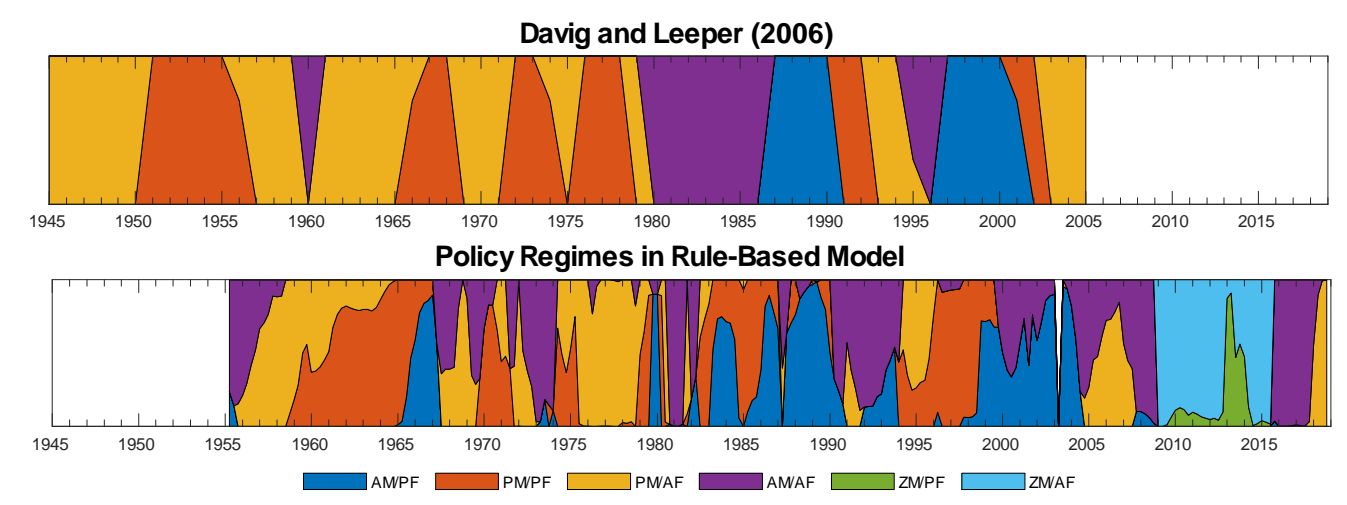

Figure 2: 'Dance' of Macro Policies in the US. Rule-based model.

starting with terrorist attacks and recession, two tax cuts in 2001 and 2003 firmly put fiscal policy into active mode with the subsequent build-up of public debt.

The Obama administration's fiscal policy was pursued at a ZLB for interest rates. The fiscal stimulus of 2009 keep fiscal policy firmly in an active mode and lead to a significant increase in debt levels. Debt accumulation slows down after the adoption of the Budget Control Act of 2011 and automatic budget sequestration. Fiscal policy remains largely active until the end of the sample, with one notable switch to a passive policy with the fiscal cliff in 2013.

The lift-off from the ZLB under Yellen is identified as strongly active monetary policy in times of high shock volatility. Powell becomes the Chairman of Fed in the first quarter of 2018, when the model determines a switch to passive monetary policy.

To conclude this section, we note that the policy switches in this model are in close agreement with Davig and Leeper (2006), despite different econometric techniques used in these two papers.

The upper panel of Figure 2 shows the results in Davig and Leeper (2006), and the lower panel summarizes our results. ${ }^{17}$ We both identify a high probability of the 'monetary-led' regime $\mathrm{AM} / \mathrm{PF}$ in the second half of the 1980s and in the late 1990s - early 2000s. ${ }^{18}$ We also discover a short episode of this policy in the mid-1960s.

The 'fiscally-led' PM/AF regime occurred during the 1956-65 decade and periodically appeared during the 1970s. In the era of Great Moderation, there are two notable episodes of this policy: in 1994-95 and around 2005. All of these periods are identified by both models.

'Mixed regimes' are less consistent between the two models. Importantly, we identify the

\footnotetext{
${ }^{17}$ We construct this figure by keeping only the two most probable regimes.

${ }^{18}$ Terms 'monetary-led' and 'fiscal-led' were introduced in Bianchi and Melosi (2017) to emphasize the key role of the corresponding policy in the mix.
} 
growing presence of explosive fiscal regime (AM/AF), starting in the early 2000s, but becoming the dominant regime from the time of the financial crisis of 2008 until the switch to passive monetary policy implemented by Powell. This period is outside of the sample in Davig and Leeper (2006).

\subsection{The Optimal Policy Model}

Estimation of the model under optimal policy yields regime switches shown in Figure 3. Switches in monetary policy in Panel A are very obviously structured into the three eras. The dominance of the less conservative monetary regime in the first era disappears with the change to the Great Moderation in the early 1980s, and the lift-off from the ZLB indicates its re-emergence. ${ }^{19}$ Fiscal policy shows more variation, see Panel B. It is also instructive to look directly at the paired monetary and fiscal regimes, the policy 'dance', reported in Panel C. This Panel, as we discuss below, demonstrates substantial consistency with Romer and Romer (2010) narrative of the legislative tax changes in the US.

The dominance of doves in the first era is quite strong and uniform. Throughout the era, dovish monetary policy was mostly combined with a less conservative fiscal policy. This mix has a natural division of stabilization responsibilities, while monetary policy is moderately inflationconservative, and fiscal policy is most concerned with stabilization of the real activity. While maintaining some surprise inflation, a relatively loose monetary policy did not pose any particular problems for fiscal debt stabilization.

However, there are some exceptions to the dominant policy mix. There is a relatively long period of conservative fiscal policy, which begun during the Eisenhower administration and continued until the mid-1960s. A more conservative fiscal policy has policy objectives that are more aligned with monetary preferences, which leads to an even more efficient sharing of stabilization efforts, resulting in a more stable economy, as measured by low inflation observed during this period. This period ends with the long-run growth-motivated Kennedy-Johnson tax cuts in 1962-64, which was implemented much later than planned, in times of higher than normal levels of economic activity. The model sees it as switch from a policy mix with stronger stabilization-driven fiscal policy back to the dominant regime of less conservative monetary and fiscal policies. The economy remained in this regime during the rest of the 1960s and in the 1970s, when the positive effects of higher spending on output and the supply-side effect of taxes on inflation during the

\footnotetext{
${ }^{19}$ The literature that studies optimal policy switches in pre-ZLB history, Chen et al. (2017), also delivers similar conclusions.
} 

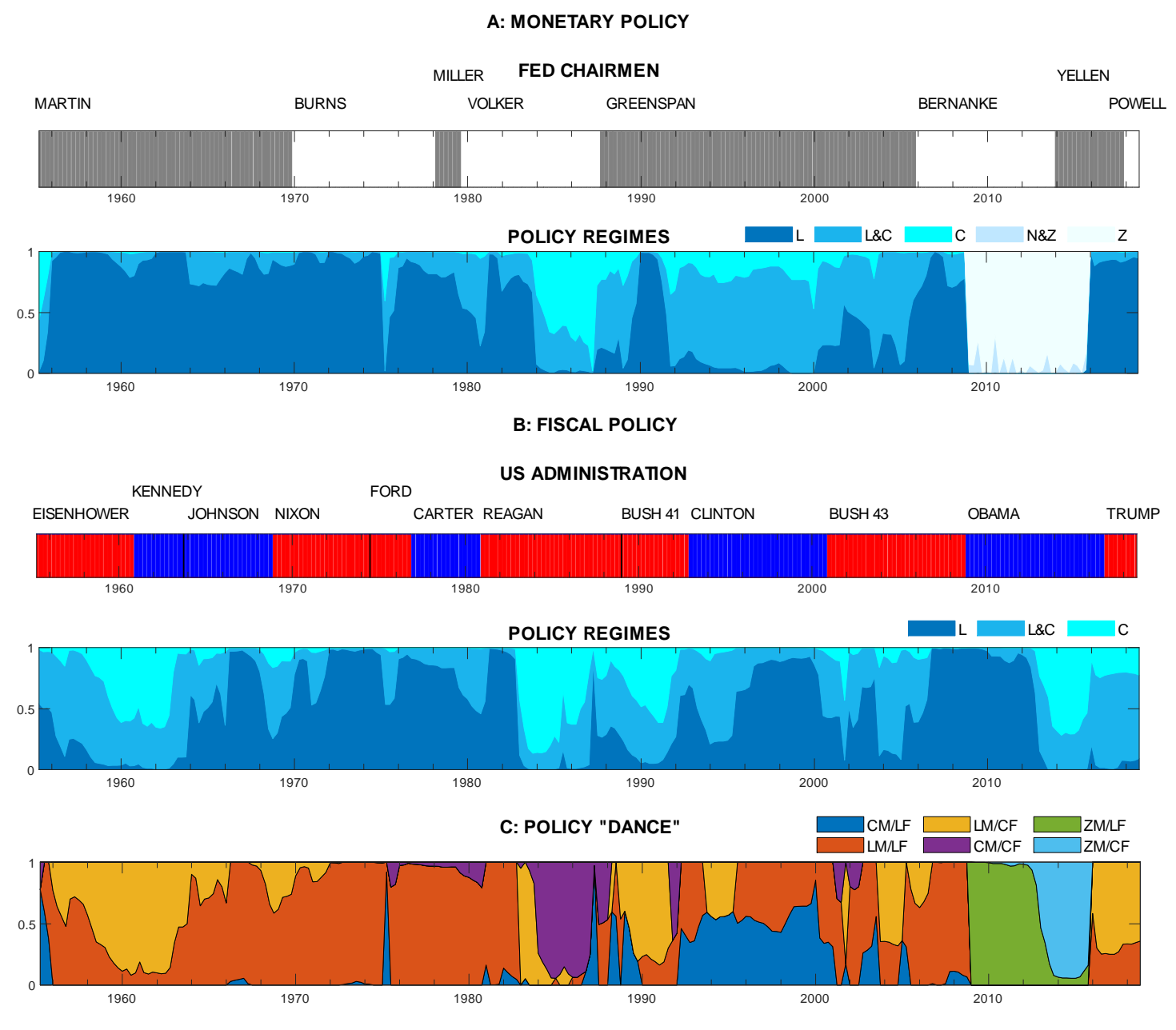

D: SHOCK VOLATLITY

US RECESSIONS
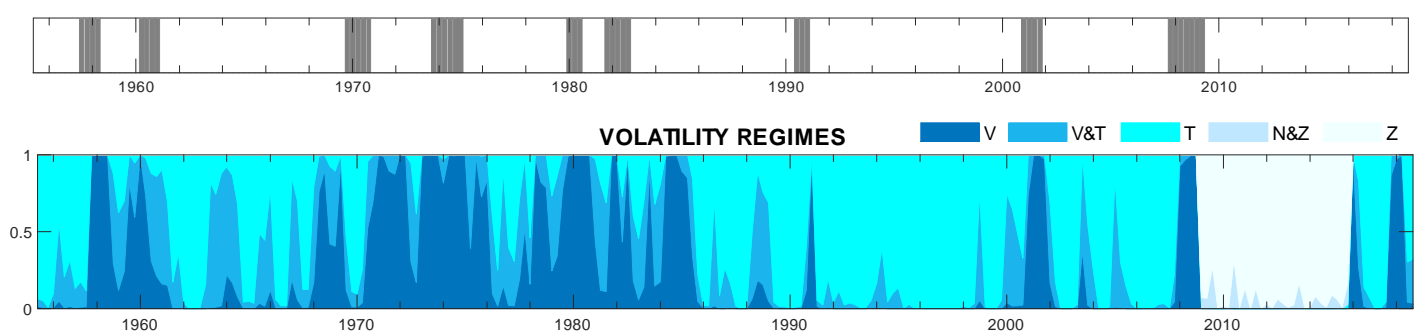

Figure 3: Regime switches, Optimal policy 
Vietnam War kept fiscal policy in the less conservative mode. Moreover, high oil prices in the 1970s and the lack of an output-inflation trade-off when using a supply-side instrument like a tax rate make it difficult to distinguish between different degrees of fiscal conservatism. Two other notable exceptions to the benchmark policy mix happen in 1955 and in 1975, following the cut of 1954 and the Ford tax rebate, respectively. In these periods, monetary policy is identified as conservative, otherwise a sharp decline of inflation cannot be explained.

A breakthrough in macroeconomic theory, which changed the view about the 'true' model of the economy, shifted the burden of short-run macroeconomic stabilization from fiscal to monetary policy and led to significant changes in the development of policies with a lower and more stable inflation even for doves, see e.g. Romer and Romer (2002). The second era of the Great Moderation starts with an extremely inflation-conservative monetary policy around 1984 and until the end of Volcker's term as a Fed Chairman in 1987. The most significant tax cut in this era was the Reagan Economic Recovery Tax Act of 1981. It was a multi-year program to stimulate long-run growth, and the current economic conditions played little role in the administration's support for the cut (Romer and Romer, 2010). Consistently, the model describes this period as a combination of conservative monetary and fiscal policies, which led to an exceptional decrease in inflation, surpassing anything that was observed in any other episode, described by a more frequent policy mix with stabilization-driven fiscal policy.

There is considerable uncertainty about the exact type of the monetary policy maker in the office at the beginning of the Greenspan term. Istrefi (2019) reports that Greenspan was expected to behave like a hawk, but revealed to be a 'swinger', being a hawk at the beginning of his term with a gradual change to a dove. In our analysis, a similar conclusion is confirmed by evidence of significant uncertainty regarding the type of Greenspan policy, where strong inflation conservatism appears to prevail in 1987-89, a dove is virtually eliminated in 1995-2000, but then the hawk is nearly ruled out in 2000-06, while some of loose monetary policy remains. ${ }^{20}$ The Clinton administration period is a textbook example of a deficit-reduction program. The gradual increase in the effective tax rate turns fiscal policy into the less conservative mode with little uncertainty. Mixing inflation-conservative monetary policy with less-conservative fiscal policy requires stronger debt stabilization efforts by fiscal policy in order to mitigate debt sustainability issues implied by a persistently high interest rate.

George W. Bush's fiscal policy in the mid-2000s shows the clear presence of conservative fiscal

\footnotetext{
${ }^{20}$ Turning nearly completely dove around times of 1990 recession is a common finding in the literature and does not preclude us to observe the transition of Greenspan from a hawk to a dove.
} 
policy. Romer and Romer (2010) identify that 2001 and 2003 tax cuts were long-run growth motivated, but also with a stabilization-driven fiscal component in 2001. The model shows a mixture of very temporary regimes in 2001-2003: spikes of a conservative monetary and fiscal policy mix that was also associated with the long-run growth motivated Reagan's tax cut, and spikes of a more stabilizing mix of less inflation conservative monetary and conservative fiscal policies, which also dominated the Eisenhower administration, in otherwise relatively neutral benchmark policy mix of less conservative monetary and fiscal policies.

We identify Bernanke's policy in the pre-ZLB period as distinctly dovish, consistently with him being seen as 'a deflation fighter rather than inflation warrior' given his widely known 'pro growth' concerns, see the analysis of media records in Istrefi (2019). There is a significant loss in monetary inflation conservatism in 2005-07, and less conservative monetary and fiscal policy mix dominates until the start of the ZLB episode in 2009. In 2009Q1 the economy enters the ZLB monetary regime, where it remains until 2016Q1. We find very little uncertainty in this regime, with only small contamination of the brightest area in Panel A.

In the third era, the post-ZLB period in monetary policy is identified as less inflation conservative with $95 \%$ certainty. A transfer from Yellen to Powell is not identified as a switch in the monetary regime. On the one hand, Powell was widely believed to have similar views with Yellen (Davies, 2017), so no change in the type of policy maker should be expected. On the other hand, evidence of Trump's attempts to undermine the Fed's independence by twitting demands of an expansionary monetary policy, thus manipulating at least some market expectations (Bianchi et al., 2019) and perhaps resulting in Powell's decisions to avoid forecasted interest rate hike three times, signals Powell's type as dove, consistently with what we (and Istrefi, 2019) identify for Yellen. The type of fiscal policy of the Trump administration is rather conservative, but there is a large degree of uncertainty.

Finally, shifts in fiscal policy modes are shown to be an important identification factor for monetary policy, they ensure that the discovered pattern of monetary shifts and separate episodes since the start of the Great Moderation are in extremely close agreement with recent findings in Istrefi (2019) and Bordo and Istrefi (2018), despite the fact that their conclusions about the type of the Fed policy are based on a completely different type of evidence (qualitative information, a narrative record in media) and the method of inference. Although Istrefi (2019) finds more inflation-conservative preferences of the first-era Fed than we do, the view of the 'true' model of the economy in those days was very different (Romer and Romer, 2002), which must have led to a change in the perception of the Fed's objectives in the first era, which is reflected in the media. 


\subsection{Summary}

Although the pattern of policy switches is different in both models, the information they present makes the overall picture more comprehensive. For instance, the Reagan administration post1982 period is identified as a conservative and concerned with long-run growth, but also fiscally responsible, fiscal policy. The effective tax rate was gradually increasing in 1983-87, consistently with passive fiscal policy and deficit concerns, although it persisted at a relatively low level since the long-run growth motivated 1981 tax cut, with no significant pressure on cost-push inflation. In contrast, gradual increase in the effective tax rate during the Clinton administration turns fiscal policy into the stabilization- and deficit-driven policy mix with little uncertainty. However, as taxes continue to rise, fiscal policy is also identified as passive by the rule-based model. Another example is that although Yellen and Powell are both clear doves, the rule-based model suggests that Powell pursued an extreme form of less inflation conservative policy, a passive monetary policy.

The consistency of the results is also apparent from panels $\mathrm{C}$ in Figure 1 and Panel D in Figure 3 which show that the smoothed probabilities of volatility modes are nearly identical to each other and extremely similar to those reported in the literature, in particular in Bianchi and Melosi (2017), despite many differences in models, policy frameworks and approaches to the econometric inference. ${ }^{21}$ A significant decrease in the volatility of shocks marks the end of the Great Inflation and the beginning of the Great Moderation in the mid-1980s, with only occasional spikes in volatility mainly associated with the recession of 2001 and 2008. The departure from the ZLB was into the short period of high volatility shocks, and another such period occurred in the first couple of quarters of Powell as chairman of the Fed.

Despite the remarkable consistency between the two models, a comparison of log marginal data densities in Table A1 shows a strong evidence in favor of the optimal policy model. A more detailed analysis in OApp I suggests that a significant component of the difference in the log marginal densities is attributed to the ZLB episode. Although there is no problem to identify the episode, the data are more consistent with its description by the optimal policy model than by the rule-based model.

\footnotetext{
${ }^{21}$ Debortoli and Lakdawala (2016) also obtain nearly identical volatility switches, with a switch to high volatility regime when ZLB was hit.
} 
Table 3: The Color of Fiscal Policy: In-sample correlation

\begin{tabular}{ccc}
\hline \hline \multirow{2}{*}{ Republican dummy } & $\mathbb{P}$ (active fiscal policy) & $\mathbb{P}$ (conservative fiscal policy) \\
& 0.1211 & 0.1206 \\
& {$[0.0469,0.1975]$} & {$[0.0109,0.2412]$} \\
\hline \hline
\end{tabular}

Note: $95 \%$ confidence interval is in brackets.

\section{Red and Blue}

The naked-eye observations of Panel B in Figure 1 suggest that there is a positive correlation between Democratic governments and fiscal responsibility: fiscal policies under Kennedy-Johnson and Clinton administrations are strongly passive, and there are short episodes of passive fiscal policy during Carter and Obama presidencies. Figure 3 and the narrative for the optimal policy model also indicate a positive correlation between the color of the incumbent political party and the type of fiscal policy objective mix: the conservative fiscal regime tend to apply during periods of Republican administrations. Indeed, fiscal policy under administrations of Eisenhower and Reagan-Bush is identified as strongly conservative, while there is no convincing evidence of less conservative fiscal policy under the administrations of George W. Bush and Trump.

These observations are formally confirmed in Panel I in Table 3. The first column presents insample correlation of probability of active fiscal policy with a political dummy switching on when the President is a Republican. The second column presents in-sample correlation of this political dummy with probability of being fiscally conservative. Both correlation coefficients are positive and statistically significant at $95 \%$ confidence level, confirming the naked-eye observations. ${ }^{22}$

Political economy models can provide an intuition of why Republican and Democratic governments decide to react differently to debt, and why the color of fiscal responsibility is blue. For example, Persson and Svensson (1989) suggest that debt can be used strategically when a party which may lose the election wants to constrain the other party governance. Left-wing parties can choose higher taxes and create a surplus to stimulate the right-wing party, when in power, to spend more on public goods. In another example, Muller et al. (2016) use an overlapping generations model and suggest that different fiscal preferences for the provision of public goods - and therefore for deficit and debt - are determined by different age composition of the left and right supporters. Using a similar observation period for US fiscal policy and employing regression analysis, they test the implied fiscal policy behavior and find that Democratic presidencies are associated with faster decline in the debt-to-output ratio, as our model also suggests.

\footnotetext{
${ }^{22}$ The correlation statistics is computed using MCMC results.
} 
A different strand of literature may suggest why we get that the color of fiscal conservatism is red. Right-wing parties are known to have preferences for smaller government size together with the concern about long run growth, see e.g. Blais et al. (1993) and Romer and Romer (2010), as well as for stable (low) inflation, as it preserves real income of lenders. Multi-year Reagan and George W. Bush Republican tax cuts were growth-driven. For a long period of two eras, when inflation gradually reduced from very high levels to the upper proximity of a relatively low inflation target, the Republican program of tax cuts, motivated by long run-growth and the 'smaller government', was not incompatible with preferences for 'low and stable inflation'. In an inflation-above-the-target environment, a model with supply-side effects of distortionary taxation makes it difficult, if at all possible, to separate these preferences. Two long episodes following Reagan and George W. Bush growth-driven tax cuts, and the counter-cyclical fiscal policy under the Eisenhower administration lead to a statistically significant positive correlation between fiscal conservatism and political red color.

\section{Understanding the Zero Lower Bound}

In this section, we expose economic mechanisms of the estimated models to better understand macroeconomic policy at the ZLB.

\subsection{Shock Which Puts Interest Rate on the Constraint}

The federal funds rate was cut to $0.5 \%$ in $2008 \mathrm{Q} 3$, setting it to the ZLB constraint where it remained until the lift-off in 2016Q1. Which shock was responsible for this drastic cut in the interest rate? Bianchi and Melosi (2017) demonstrate that the ZLB was hit when an extremely large (discrete) negative demand shock arrived. We come to a similar conclusion, although our model does not distinguish discrete and continuous shocks. Using the rule-based model, we identify an extremely large negative taste shock that occurs at the end of 2008 and gradually decays throughout the entire episode of the ZLB, see OApp H. In this model taste shock plays the role of demand shock. In the optimal policy model, however, taste shocks are efficient, they shift natural rates of real variables and are not directly comparable to taste shocks in the rulebased model. The role of a demand shock is taken by a government spending shock, and we identify the arrival of a large negative spending shock in the last quarter of 2008. In both models, if a large demand shock did not arrive, the ZLB would not be hit, as shown in Figure 4. This figure plots the results of a counter-factual experiment, in which the demand shock (taste shock in the rule-based model and government spending shock in the optimal policy model) is set to 

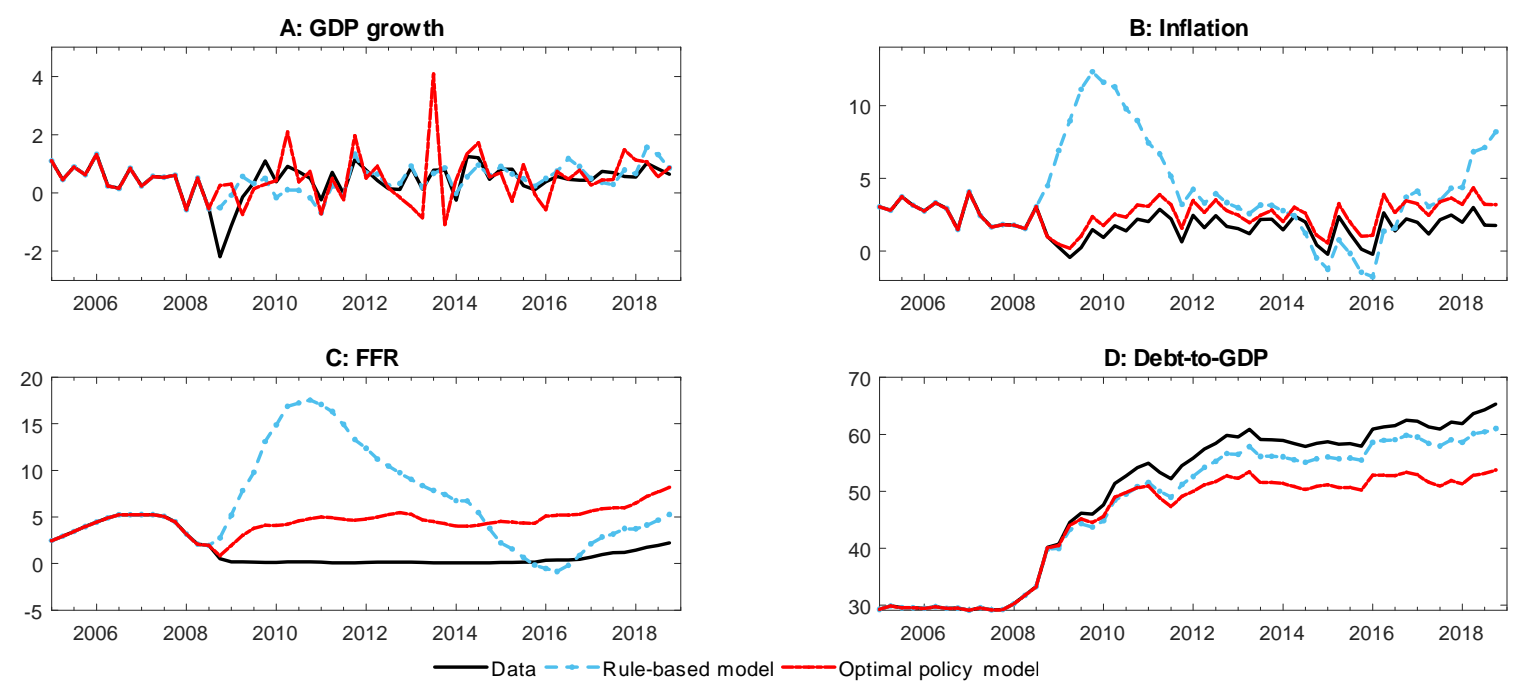

Figure 4: Effects of a large negative demand shock in 2008Q4.

zero from 2008Q4 until the end of the sample. As there is no need to impose the ZLB, monetary policy is set to the active mode in the rule-based model and to the less conservative mode in the optimal policy model. ${ }^{23}$ In this figure Great Recession of 2009 never happens.

\subsection{The Relevance of the Zero Lower Bound Constraint}

The short term interest rate remained at the ZLB for long period of seven years. Did it constrain monetary policy? To address this question we conduct a series of counter-factual simulations, plotted in Figure 5. For each model, we consider a possible early lift-off from the constraint. We chose several dates for a lift-off, distributed through the whole episode. We start in 2008Q4 and check if the Fed with either conventional hawk and dove preferences, or reacting with either active or passive monetary rule, would have departed immediately. We then rerun simulations by delaying the lift-off by half a year at each next run. For each attempt to leave the constraint we plot the counter-factual interest rate for three quarters for each type of the monetary policy maker. Importantly, in these simulations we apply the estimated ZLB shocks in 2008Q4-2015Q4.

The optimal policy model (Panel A) suggests that the constraint was binding for the conservative monetary policy maker, since they would have cut the interest rate by about 2 percentage points more at every time period. An early lift-off could only be implemented in 2013 by a less

\footnotetext{
${ }^{23}$ These modes of monetary policy are chosen for illustrative purposes, they were in place just before and just after the ZLB. The other modes - passive and inflation-conservative - deliver similar results where interest rate remain strongly above the ZLB for several years after 2008Q3.
} 
conservative monetary policy maker, but the interest rate would have crashed back into the ZLB
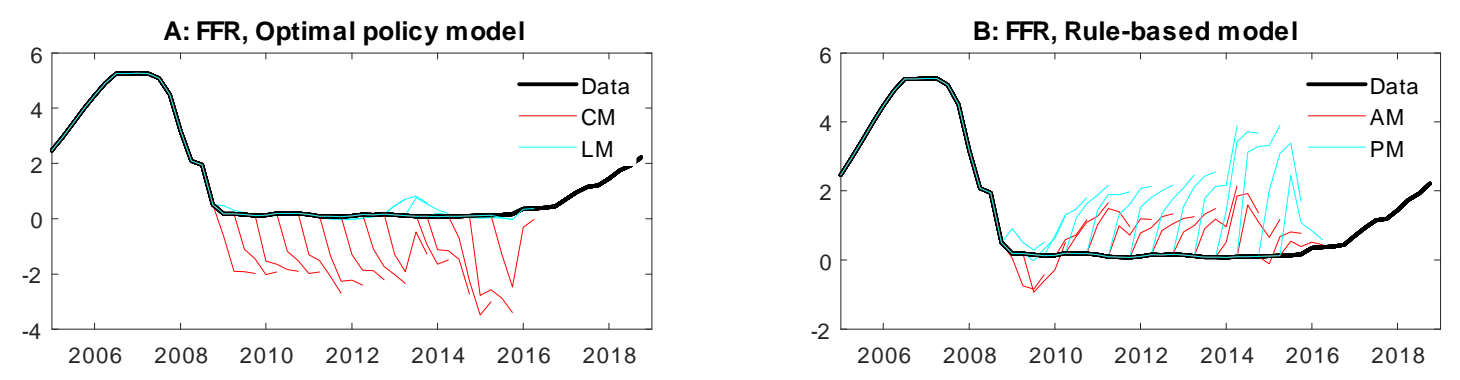

Figure 5: Effects of an early take-off from the zero lower bound.

only a few quarters later. Overall, dovish monetary policy seems more consistent with keeping interest rate on the ZLB, provided shocks are correctly identified. If monetary policy was conducted by a dove during this period, an observer would see just a switch to a well-known type of monetary policy with well-known implications for macroeconomic volatility, rather than detect an extraordinary regime. In particular, the level of inflation would be consistent with monetary policy conducted by a dove. In this sense, our findings may look consistent with Debortoli et al. (2019).

It is worth noting, however, that in these simulations we keep ZLB-shocks and transition probabilities of the Markov processes as estimated, so finding a great similarity between monetary policy of a dove and the zero-interest-rate policy does not imply the inability to identify them in estimation. When estimating, these two policies have different transition probabilities and imply different shock processes. This counter-factual experiment shows that the ZLB constraint was very relevant for a hawk, whose actions were severely restricted in 2008-2015, and the identification of the more conservative monetary regime relied on the existence of two other monetary regimes. OApp I shows that if we re-estimate the model without the ZLB regime, then there is large reduction in the marginal data density. Furthermore, the implied probabilities of policy regimes produce more noisy picture, despite simpler model and similar parameter estimates.

In contrast, the rule-based model (Panel B) suggests that an early lift-off could be safely implemented after mid-2010 by either active or passive monetary policy maker, so the ZLB was not binding after the first year on the constraint. The way we estimate regimes by almost 'gluing' the interest rate to the bound is only slightly less strict than imposing the dates of the ZLB as in Bianchi and Melosi (2017). It agrees well with the optimal policy model, and not so well with the rule-based model. This finding provides a possible explanation of the much lower marginal 
data density of the rule-based model compared to the optimal policy model.

\subsection{Monetary Policy Uncertainty and Inflation at Zero Lower Bound}

We find frequent changes of policy preferences, but how important is the uncertainty about future policy for the dynamics of inflation at the ZLB? In this section we show that beliefs that future hawkish monetary policy will be able to bring inflation up to the target may have kept current inflation relatively high.

Consider the optimal policy model. The ZLB was only mildly constraining the less inflationconservative monetary policy maker (Section 7.2), and the lift-off from it was steered by monetary doves (Figure 3), as hawks would prefer to keep interest rate below zero for longer. Hawks, therefore, seem to play no important role in the ZLB period. But how important was it to know that monetary policy could be run by hawks? To quantify this effect, we run the following counter-factual experiment. We keep fiscal policy as estimated and reduce uncertainty about future monetary policy, starting from the beginning of the ZLB episode. We assume that the more inflation conservative monetary policy becomes irrelevant and the less conservative mode is the only possible monetary mode in N-regime. ${ }^{24}$

Figure 6 demonstrates that eliminating uncertainty about the type of monetary policy maker reduces inflation during nearly the whole ZLB episode, but extends this episode. It also raises inflation slightly during the lift-off.

With interest rate on the constraint, a reduction in inflation can be attributed to either expectations effects of a low future inflation, or to the reduction in the effective tax rate, which reacts to the change in uncertainty. Both work in the same direction.

Indeed, on the ZLB constraint and with inflation running below the target, the private sector used to attach a non-zero probability to the next-period monetary hawk. The hawk would want to reduce interest rate further down and so move inflation up, closer to its target. Once we eliminate this option and reduce uncertainty, then inflation stays low. By the same token, as there is no hawk to cut the interest rate, the perceived (negative) output gap increases. As the fiscal policy maker is more output-averse than monetary, they lower the tax rate, which has deflationary effect. As inflation is now lower, even a dove will want to reduce interest rate below zero. The lift-off needs to be delayed, as the counter-factuals illustrate. When the dove finally starts raising interest rate - we show that a delay of four quarters is enough - a fiscal policy

\footnotetext{
${ }^{24}$ When computing counterfactuals, this is modelled with imposing transition probabilities $p_{l l}=1, p_{c c}=p_{c z}=0$, starting in Z-regime and assuming all future types of the monetary policymaker are either Z or L.
} 

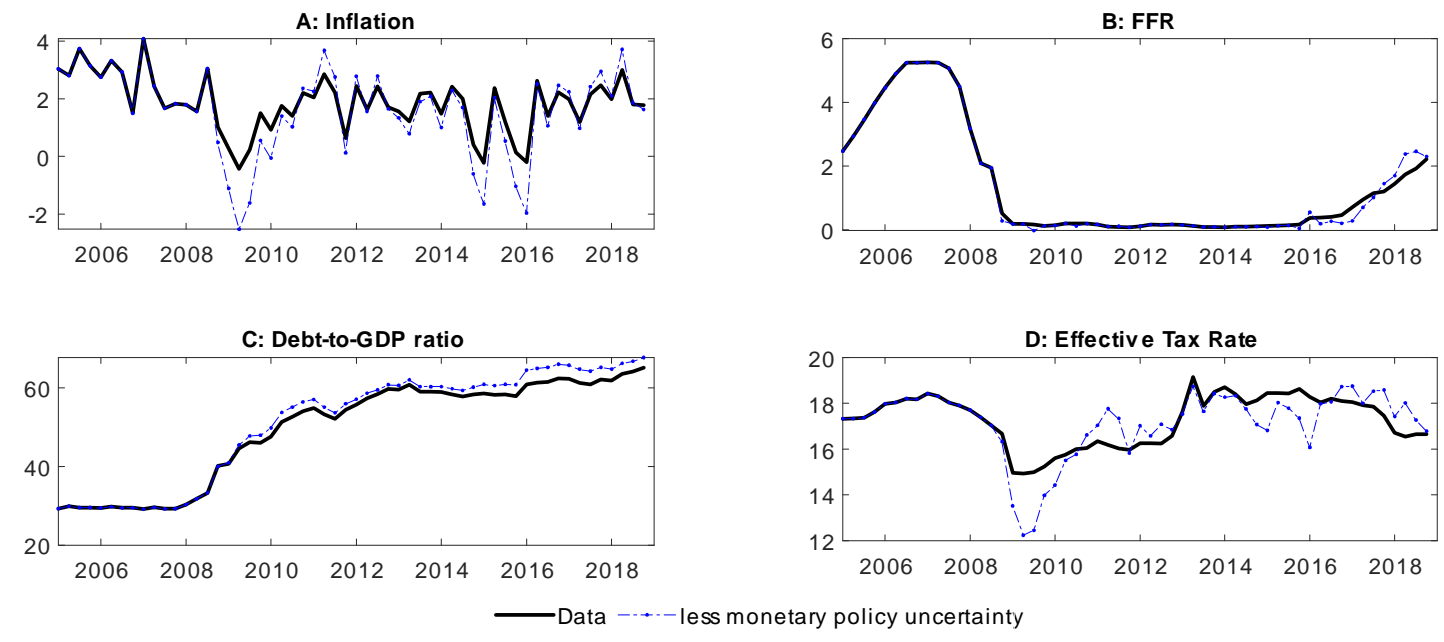

Figure 6: The effect of monetary policy uncertainty

maker that is inflation-conservative in this period is helping to raise inflation by raising taxes, thus pushing inflation up.

\subsection{Defeating Zero Lower Bound}

The ZLB had a substantial effect on the dynamics of the economy. The lift-off did not bring the desired room for monetary policy to operate and there is a fear that this constraint may become very frequent in the future. We need to know the range of weapons available to defeat it. Policy delegation may become one of them.

Discretionary monetary policy is sub-optimal; delegating it to a policy maker with objectives that are different from social can improve social welfare. ${ }^{25}$ Among several delegation schemes, price level targeting (PLT) has already attracted a lot of attention as a potential policy to avoid the ZLB constraint. ${ }^{26}$ PLT can be formally described by a policy objective in the form of (8) where the quadratic in inflation term is replaced with quadratic in price and inflation term, which

\footnotetext{
${ }^{25}$ Examples include speed limit policy Walsh (2003), conservative central bank Rogoff (1985), interest rate smoothing Woodford (2003b) and price level targeting Svensson (1999).

${ }^{26}$ See e.g. Williams (2016), Bernanke (2019), and Svensson (2020).
} 
describes how deviation of price from the desired price level is punished, see OApp J,

$$
\begin{aligned}
L^{M} & =\mathbb{I}_{N} \mathbb{E}_{0} \sum_{t=0}^{\infty} \beta^{t}\left(\omega_{\pi}^{M}\left(\varsigma_{M}\right)\left((1-\lambda)\left(\hat{\pi}_{t}^{2}+\frac{\zeta}{\alpha(1-\zeta)}\left(\Delta \hat{\pi}_{t}\right)^{2}\right)+\lambda \hat{p}_{t}^{2}\right)\right. \\
& \left.+\omega_{x}\left(\hat{x}_{t}+\hat{\xi}_{t}\right)^{2}+\omega_{y}^{M}\left(\hat{y}_{t}-\frac{\sigma}{\varphi} \hat{\xi}_{t}\right)^{2}+\omega_{i}\left(\Delta \hat{\imath}_{t}\right)^{2}\right)+\mathbb{I}_{Z} \mathbb{E}_{0} \sum_{t=0}^{\infty} \beta^{t}\left(\hat{\imath}_{t}-\hat{\imath}_{t}^{Z}\right)^{2} .
\end{aligned}
$$

When targeting a price level, bygones are not bygones, and an inflation hike must follow a deflation. Crucially, in a Rational Expectation equilibrium, monetary policy is expected to punish inflation hikes with higher interest rates that would stay high for longer. Therefore, the private sector will deviate less from the inflation rate consistent with the desired price level path, and so the interest rate will not need to deviate much from its long run level to correct for bygones. ${ }^{27}$ Overall, discretionary PLT generates much smaller volatility of inflation and interest rate than discretionary inflation targeting around the respective long run levels, nearly mimicking the solution under monetary commitment. This is why PLT is likely to defeat the zero low bound constraint: once the policy is fully credible and the Rational Expectations concept is applicable, leaving the ZLB will begin with the central announcement of switching to price level targeting. Inflation will adjust quickly up towards its long run rate consistent with the chosen price level path, and interest rate will move up towards its long run level. However, will fiscal policy - supply-side effects of distortionary taxes, and expectation effects of debt accumulation - compromise the proposal to target price levels?

Panel I in Figure 7 shows the results of a series of counter-factual simulations with different dates for price level targeting announcements. Specifically, for each date, we assume that the private sector anticipates the following monetary modes: policy maker $\mathrm{C}$ conducts an inflation targeting policy with the estimated objectives, policy maker L changes its mandate and conducts a price level targeting policy, and Z-regime. We keep transition probabilities between C, L and $\mathrm{Z}$ regimes as estimated. We also assume that policy maker $\mathrm{L}$ is in charge, starting from the announcement date and until the end of the sample, and plot only three periods after such announcement at each date. At the time of the announcement, inflation - driven by expectations consistent with the PLT policy - goes up, and interest rate follows, rising by 1-2 percentage points. Monetary policy wants to keep interest rate below the long run rate, maintaining pressure on inflation to move close to the rate consistent with the price level target. With higher inflation, optimal interest rate does not need to stay low and should rise. A switch to PLT, therefore,

\footnotetext{
${ }^{27}$ The same logic works when inflation is below the target even if near the ZLB. Interest rate may stay at the ZLB for longer to generate the desired excess inflation.
} 

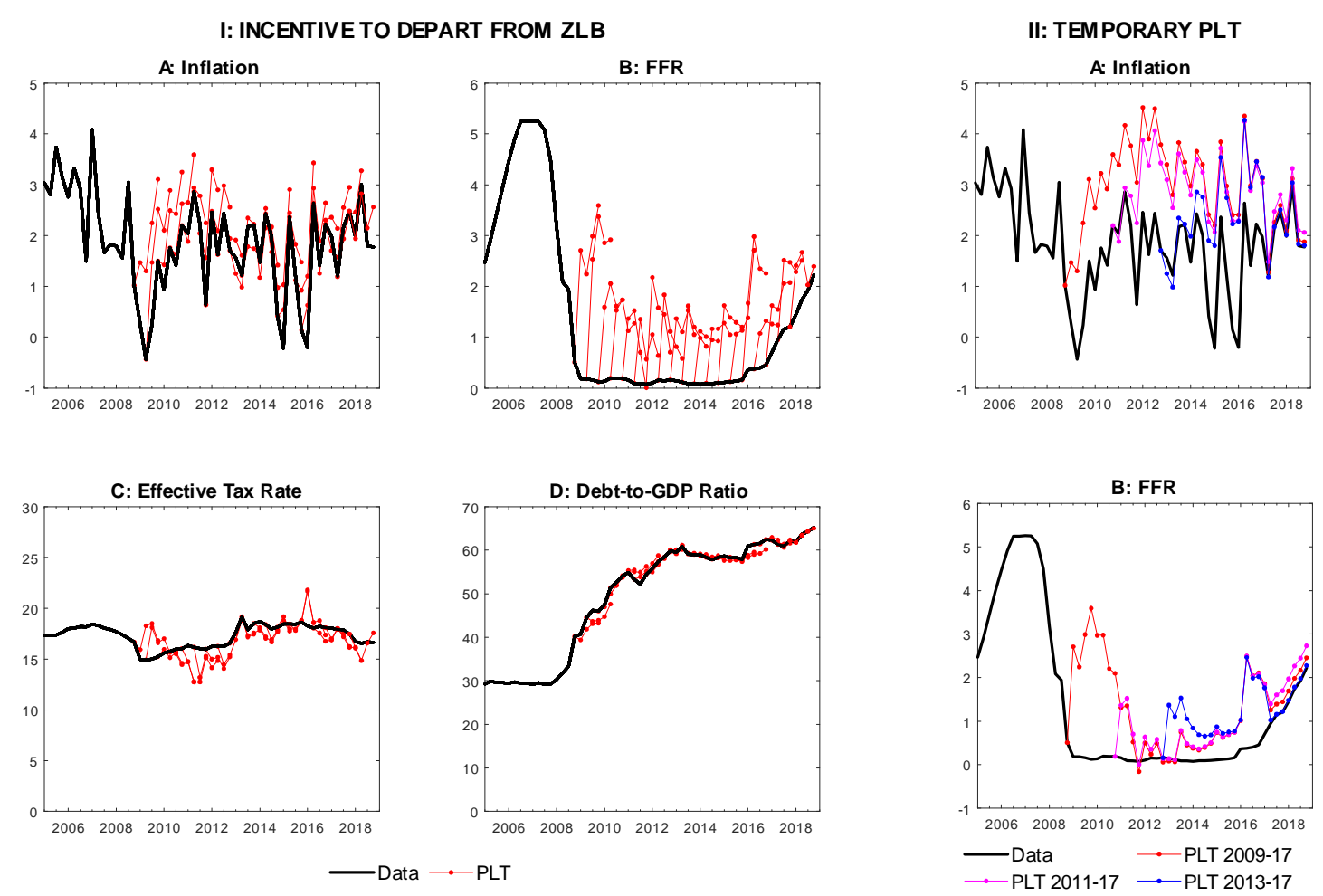

Figure 7: Price Level Targeting

generates an immediate lift-off from the ZLB constraint.

Fiscal policy does not compromise the PLT lift-off from the ZLB, even if taxes fall to prevent destabilizing effects on output. Panels $\mathrm{C}$ and $\mathrm{D}$ suggest that volatility of taxes remain similar to what is observed in the data, and there is only small effect on government debt. Bai et al. (2017) reach a similar conclusion in a theoretical model.

Bernanke (2017) discusses that most likely, this policy will only be needed in times of - possibly frequent - ZLB constraints. Once the threat of such a period is over, it would be desirable to move back to conventional inflation targeting. This is what we ask next: once price level targeting is operational - but also uncertain as there are other policy options - what to expect and when to exit? Panel II plots three counter-factual simulations of the same scenario as in Panel I: the price level targeting is conducted by policy maker $\mathrm{L}$, this regime starts at three different dates, in 2009, 2011 and 2013, but in each case policy maker L changes the mandate back in 2017 and then implements inflation targeting with the estimated objectives. Panel II demonstrates that, once the period of price level targeting is over and policy maker $\mathrm{L}$ changes the mandate back in 
2017, the economy returns close to the path it would have taken if there had been no change in the mandate. In our scenarios, this change occurs when the actual interest rate rose, so there is room for such a reduction in the interest rate. This experiment demonstrates that a temporary policy regime of price level targeting should last longer than the ZLB regime it is defeating.

Finally, there is a concern that changing policy target leads to time-inconsistency. Without denying the problem, we note that counterfactuals in Figure 7 were obtained under the assumption of a hybrid PLT, with relatively small coefficient on the price level term $\lambda=0.25$ in formula (12), so that the original inflation target has not been completely abandoned. There is also policy uncertainty, as monetary policy targets are expected to change in the future. Even with positive probability of reneging on the PLT in the future, a potentially temporary switch to the PLT results in more stable inflation and higher interest rate. Therefore, the hybrid feature of the PLT, together with policy uncertainty may alleviate the time-inconsistency problem of changing the policy target.

\section{Conclusion}

This paper studies monetary and fiscal policy interactions in the US using a small-scale DSGE model of non-cooperative monetary and fiscal policy and more than 60 years of the US macroeconomic data. We describe policy making in terms of targeting rules and assume that policy preferences can change over time, as described by Markov switching, to capture changes in the underlying model used by policy makers, including those driven by ideological pressures on fiscal policy.

Estimating this model pursued two main aims. The first aim was to understand the monetary and fiscal policy mix, identify preferences of modern policy makers, and create the basis for the subsequent policy analysis of contemporary economic problems. The second was to analyze the effect of the zero lower bound for interest rate on the economy and suggest a potential improvement for the current policy framework of inflation targeting, bearing in mind that the next zero lower bound episode is likely to be just around the corner.

We find that fiscal policy is an important factor in identifying monetary policy, but it is also shaped by the political color. We demonstrate that the color of fiscal responsibility is blue, and confirm that optimal fiscal policy that is most consistent with low inflation, but also with long run output growth concerns, happened under the red party color.

The results of this paper identify the restrictive nature of the zero lower bound constraint for monetary policy. We show that policy uncertainty played a substantial role in explaining the 
dynamics of inflation on the constraint. We also demonstrate that by changing inflation targeting to price level targeting, the Fed could have left the constraint at any chosen time. This finding may become more policy-relevant once the next zero low bound episode arrives and a quick lift-off is needed.

\section{References}

Alesina, A., N. Roubini, and G. D. Cohen (1997). Political Cycles and the Macroeconomy. Cambridge, MA: MIT Press.

An, S. and F. Schorfheide (2007). Bayesian Analysis of DSGE Models. Econometric Reviews 26 (24), 113-172.

Bai, Y., T. Kirsanova, and C. Leith (2017). Nominal targeting in an economy with government debt. European Economic Review 94, 103-125.

Bank of Canada (2011). Renewal of the Inflation-Control Target: Background Information - November 2011. Bank of Canada, https://www.bankofcanada.ca/wpcontent/uploads/2011/11/background_nov11.pdf.

Bernanke, B. S. (2017). Monetary Policy in a New Era. Brookings Institution, https://www.brookings.edu/research/monetary-policy-in-a-new-era/.

Bernanke, B. S. (2019). Evaluating lower-for-longer policies: Temporary pricelevel targeting. Brookings Institution, https://www.brookings.edu/blog/benbernanke/2019/02/21/evaluating-lower-for-longer-policies-temporary-price-level-targeting/.

Bianchi, F. and C. Ilut (2017). Monetary/Fiscal policy mix and agents' beliefs. Review of Economic Dynamics 26, 113-139.

Bianchi, F., T. Kind, and H. Kung (2019). Threats to Central Bank Independence: HighFrequency Identification with Twitter. NBER Working Papers 26308.

Bianchi, F. and L. Melosi (2017). Escaping the Great Recession. American Economic Review 107(4), 1030-1058.

Blais, A., D. Blake, and S. Dion (1993). Do Parties Make a Difference? Parties and the Size of Government in Liberal Democracies. American Journal of Political Science 37(1), 40-62.

Blake, A. P. and T. Kirsanova (2011). Inflation-Conservatism and Monetary-Fiscal Policy Interactions. International Journal of Central Banking 7(2), 41-83.

Bordo, M. D. and K. Istrefi (2018). Perceived FOMC: The Making of Hawks, Doves and Swingers. NBER Working Papers 24650, National Bureau of Economic Research, Inc.

Calvo, G. (1983). Staggered Prices in a Utility-Maximising Framework. Journal of Monetary Economics 12, 383-398.

Chen, X., T. Kirsanova, and C. Leith (2017). How Optimal is US Monetary Policy? Journal of Monetary Economics 92, 96-111. 
Chen, X., E. M. Leeper, and C. Leith (2019). US Monetary and Fiscal Policies - Conflict or Cooperation? University of Glasgow Discussion Paper 2020-04.

Cochrane, J. H. (2017). Michelson-Morley, Fisher, and Occam: The Radical Implications of Stable Quiet Inflation at the Zero Bound. In NBER Macroeconomics Annual 32, pp. 113-226.

Committee for Responsible Federal Budget (2008). Twelve Principles for Fiscal Responsibility. Available at http://www.crfb.org/papers/twelve-principles-fiscal-responsibility.

Currie, D. and P. Levine (1993). Rules, Reputation and Macroeconomic Policy Coordination. Cambridge: Cambridge University Press.

Davies, G. (2017). Doves and hawks in the race for Fed chair. Financial Times. October, 8.

Davig, T. and E. Leeper (2006). Fluctuating Macro Policies and the Fiscal Theory. In NBER Macroeconomics Annual 21, pp. 247-298. MIT Press.

Debortoli, D., J. Gali, and L. Gambetti (2019). On the Empirical (Ir)relevance of the Zero Lower Bound Constraint. In NBER Macroeconomics Annual 34.

Debortoli, D. and A. Lakdawala (2016). How Credible is the Federal Reserve? A Structural Estimation of Policy Re-optimizations. AEJ: Macroeconomics 8(3), 42-76.

Del Negro, M., G. Eggertsson, A. Ferrero, and N. Kiyotaki (2017). The Great Escape? A Quantitative Evaluation of the FedŠs Liquidity Facilities. American Economic Review 107(3), 824-857.

Dennis, R. (2006). The Policy Preferences of the US Federal Reserve. Journal of Applied Econometrics 21, 55-77.

do Valle Costa, O. L., M. D. Fragoso, and R. P. Marques (2005). Discrete-Time Markov Jump Linear Systems. London: Springer-Verlag.

Drazen, A. (2000). The Political Business Cycle after 25 Years. In NBER Macroeconomics Annual 15 , pp. 651-678.

Evans, C. L. (2010). A Proposal for a State-Contingent Price-Level Objective. Federal Reserve Bank of Chicago, https://www.federalreserve.gov/monetarypolicy/files/FOMC20100914memo01.pdf.

Farmer, R. E. A., D. F. Waggoner, and T. Zha (2011). Minimal State Variable Solutions to Markov-switching Rational Expectations Models. Journal of Economic Dynamics and Control 35(12), 2150-2166.

Galí, J. and M. Gertler (1999). Inflation Dynamics: A Structural Econometric Analysis. Journal of Monetary Economics 44, 195-222.

Goodfriend, M. (2002). The Phases of U.S. Monetary Policy: 1987 to 2001. Federal Reserve Bank of Richmond Economic Quarterly 88(4), 1-17.

Gust, C., E. Herbst, D. López-Salido, and M. E. Smith (2017). The Empirical Implications of the Interest-Rate Lower Bound. American Economic Review 107(7), 1971-2006. 
Hibbs, D. A. (1987). The American Political Economy: Macroeconomics and Electoral Politics in the United States . Cambridge, MA: Harvard University Press.

Istrefi, K. (2019). In Fed Watchers' Eyes: Hawks, Doves and Monetary Policy. Working papers 725, Banque de France.

Kiley, M. T. and J. M. Roberts (2017). Monetary Policy in a Low Interest Rate World. Brookings Papers on Economic Activity 48(1), 317-396.

Komunjer, I. and S. Ng (2011). Dynamic Identification of Dynamic Stochastic General Equilibrium Models. Econometrica 79(6), 1995-2032.

Leeper, E. M. (1991). Equilibria Under 'Active' and 'Passive' Monetary and Fiscal Policies. Journal of Monetary Economics 27, 129-147.

Leeper, E. M. and C. Leith (2016). Understanding Inflation as a Joint Monetary-Fiscal Phenomenon. In H. Uhlig and J. Taylor (Eds.), Handbook of Macroeconomics, Volume 2, pp. 2305-2415. Elsevier.

Muller, A., K. Storesletten, and F. Zilibotti (2016). The Political Color of Fiscal Responsibility. Journal of European Economic Association 14 (1), 252-302.

Persson, T. and L. E. O. Svensson (1989). Why a Stubborn Conservative would Run a Deficit: Policy with Time-Inconsistent Preferences. The Quarterly Journal of Economics 104(2), 325345.

Powell, J. H. (2019). Challenges for Monetary Policy. Speach at the "Challenges for Monetary Policy" symposium, Jackson Hole, Wyoming, available at https://www.federalreserve.gov/newsevents/speech/powell20190823a.htm.

Rogoff, K. (1985). The optimal degree of commitment to an intermediate monetary target. The Quarterly Journal of Economics 100(4), 1169-1189.

Romer, C. D. and D. H. Romer (2002). A Rehabilitation of Monetary Policy in the 1950's. American Economic Review 92(2), 121-127.

Romer, C. D. and D. H. Romer (2010). The Macroeconomic Effects of Tax Changes: Estimates Based on a New Measure of Fiscal Shocks. American Economic Review 100(3), 763-801.

Schorfheide, F. (2005). Learning and Monetary Policy Shifts. Review of Economic Dynamics 8, 392-419.

Sims, C. A. and T. Zha (2006). Were There Regime Switches in US Monetary Policy. American Economic Review 96(1), 54-81.

Smets, F. and R. Wouters (2003). An Estimated Dynamic Stochastic General Equilibrium Model of the Euro Area. Journal of the European Economic Association 1(1), 1123-75.

Svensson, L. and N. Williams (2007). Monetary Policy with Model Uncertainty: Distribution Forecast Targeting. CEPR Discussion Papers 6331.

Svensson, L. E. (1999). Price Level targeting versus inflation targeting: a free lunch? Journal of Money, Credit and Banking 431(3), 277-295. 
Svensson, L. E. O. (2020). Monetary Policy Strategies for the Federal Reserve. International Journal of Central Banking 16(1), 133-193.

Vestin, D. (2006). Price-level versus inflation targeting. Journal of Monetary Economics 53(7), $1361-1376$.

Walsh, C. (2003). Speed Limit Policies: The Output Gap and Optimal Monetary Policy. American Economic Review 93(1), 265-278.

Williams, J. C. (2016). Monetary Policy in a Low R-star World. Economic letter, 2016-23.

Woodford, M. (2001). Fiscal Requirements for Price Stability. Journal of Money, Credit and Banking 33, 669-728.

Woodford, M. (2003a). Interest and Prices: Foundations of a Theory of Monetary Policy. Princeton, NJ.: Princeton University Press.

Woodford, M. (2003b). Optimal Interest-Rate Smoothing. Review of Economic Studies 70(4), 861-886. 
Table A1: Estimation Results

\begin{tabular}{|c|c|c|c|c|}
\hline Parameters & & $\begin{array}{r}\text { Posterior } \\
\text { Optimal }\end{array}$ & $\begin{array}{l}\text { Posterior } \\
\text { Rule }\end{array}$ & $\begin{array}{c}\text { Prior dist. } \\
\text { Type (mean,std) }\end{array}$ \\
\hline \multicolumn{5}{|c|}{ Model Parameters } \\
\hline Inv. of intertemp. elas. of subst. & $\sigma$ & $\begin{array}{c}3.070 \\
{[2.851,3.293]}\end{array}$ & $\begin{array}{c}2.899 \\
{[2.651,3.148]}\end{array}$ & $N(3.0,0.15)$ \\
\hline Inverse of Frisch elasticity & $\varphi$ & $\begin{array}{c}2.308 \\
{[2.105,2.510]}\end{array}$ & $\begin{array}{c}1.868 \\
{[1.619,2.117]}\end{array}$ & $N(2.0,0.15)$ \\
\hline Calvo parameter & $\alpha$ & $\begin{array}{c}0.774 \\
{[0.765,0.782]}\end{array}$ & $\begin{array}{c}0.761 \\
{[0.744,0.778]}\end{array}$ & $B(0.75,0.025)$ \\
\hline inflation inertia & $\zeta$ & $\begin{array}{c}0.099 \\
{[0.058,0.141]}\end{array}$ & $\begin{array}{c}0.826 \\
{[0.7379,0.863]}\end{array}$ & $B(0.5,0.15)$ \\
\hline habit persistence & $\theta$ & $\begin{array}{c}0.966 \\
{[0.959,0.974]}\end{array}$ & $\begin{array}{c}0.730 \\
{[0.670,0.778]}\end{array}$ & $B(0.5,0.15)$ \\
\hline \multicolumn{5}{|c|}{ Structural Shock Processes } \\
\hline AR coeff., taste shock & $\rho^{\xi}$ & $\begin{array}{c}0.952 \\
{[0.947,0.956]}\end{array}$ & $\begin{array}{c}0.837 \\
{[0.789,0.880]}\end{array}$ & $B(0.5,0.15)$ \\
\hline AR coeff., technology shock & $\rho^{z}$ & $\begin{array}{c}0.135 \\
{[0.106,0.166]}\end{array}$ & $\begin{array}{c}0.302 \\
{[0.233,0.3741]}\end{array}$ & $B(0.5,0.15)$ \\
\hline AR coeff., cost-push shock & $\rho^{\mu}$ & $\begin{array}{c}0.936 \\
{[0.927,0.945]}\end{array}$ & $\begin{array}{c}0.832 \\
{[0.752,0.907]}\end{array}$ & $B(0.5,0.15)$ \\
\hline AR coeff., spending shock & $\rho^{g}$ & $\begin{array}{c}0.955 \\
{[0.947,0.963]}\end{array}$ & $\begin{array}{c}0.916 \\
{[0.884,0.944]}\end{array}$ & $B(0.5,0.15)$ \\
\hline AR coeff., term premium shock & $\rho^{\nu}$ & $\begin{array}{c}0.674 \\
{[0.648,0.698]}\end{array}$ & $\begin{array}{c}0.631 \\
{[0.572,0.691]}\end{array}$ & $B(0.5,0.15)$ \\
\hline Std., taste shock & $\sigma_{\xi(T)}$ & $\begin{array}{c}1.299 \\
{[1.053,1.602]}\end{array}$ & $\begin{array}{c}0.929 \\
{[0.381,1.577]}\end{array}$ & $I G(0.25,2.0)$ \\
\hline Std., taste shock & $\sigma_{\xi(V)}$ & $\begin{array}{c}2.473 \\
{[1.977,2.980]}\end{array}$ & $\begin{array}{c}4.751 \\
{[3.468,6.336]}\end{array}$ & $I G(0.75,2.0)$ \\
\hline Std., taste shock & $\sigma_{\xi(Z)}$ & $\begin{array}{c}1.579 \\
{[1.207,2.055]}\end{array}$ & $\begin{array}{c}1.212 \\
{[0.475,2.298]}\end{array}$ & $I G(1.0,2.0)$ \\
\hline Std., technology shock & $\sigma_{z(T)}$ & $\begin{array}{c}0.597 \\
{[0.527,0.670]}\end{array}$ & $\begin{array}{c}0.346 \\
{[0.252,0.442]}\end{array}$ & $I G(0.25,2.0)$ \\
\hline Std., technology shock & $\sigma_{z(V)}$ & $\begin{array}{c}1.083 \\
{[0.918,1.222]}\end{array}$ & $\begin{array}{c}1.345 \\
{[0.971,1.860]}\end{array}$ & $I G(0.75,2.0)$ \\
\hline Std., technology shock & $\sigma_{z(Z)}$ & $\begin{array}{c}0.858 \\
{[0.665,1.079]}\end{array}$ & $\begin{array}{c}0.606 \\
{[0.451,0.797]}\end{array}$ & $I G(1.0,2.0)$ \\
\hline Std., cost-push shock & $\sigma_{\mu(T)}$ & $\begin{array}{c}0.025 \\
{[0.020,0.031]}\end{array}$ & $\begin{array}{c}0.052 \\
{[0.041,0.066]}\end{array}$ & $I G(0.025,0.2)$ \\
\hline Std., cost-push shock & $\sigma_{\mu(V)}$ & $\begin{array}{c}0.220 \\
{[0.181,0.264]}\end{array}$ & $\begin{array}{c}0.111 \\
{[0.092,0.134]}\end{array}$ & $I G(0.075,0.2)$ \\
\hline Std., cost-push shock & $\sigma_{\mu(Z)}$ & $\begin{array}{c}0.049 \\
{[0.038,0.062]}\end{array}$ & $\begin{array}{c}0.075 \\
{[0.053,0.101]}\end{array}$ & $I G(0.1,0.2)$ \\
\hline Std., spending shock & $\sigma_{g(T)}$ & $\begin{array}{c}0.238 \\
{[0.194,0.289]}\end{array}$ & $\begin{array}{c}0.216 \\
{[0.153,0.293]}\end{array}$ & $I G(0.25,2.0)$ \\
\hline Std., spending shock & $\sigma_{g(V)}$ & $\begin{array}{c}0.797 \\
{[0.657,0.953]}\end{array}$ & $\begin{array}{c}1.060 \\
{[0.761,1.440]}\end{array}$ & $I G(0.75,2.0)$ \\
\hline Std., spending shock & $\sigma_{g(Z)}$ & $\begin{array}{c}0.737 \\
{[0.580,0.914]}\end{array}$ & $\begin{array}{c}0.451 \\
{[0.304,0.644]}\end{array}$ & $I G(1.0,2.0)$ \\
\hline Std., term premium shock & $\sigma_{\nu(T)}$ & $\begin{array}{c}1.948 \\
{[1.756,2.160]}\end{array}$ & $\begin{array}{c}1.229 \\
{[0.888,1.560]}\end{array}$ & $I G(0.25,2.0)$ \\
\hline Std., term premium shock & $\sigma_{\nu(V)}$ & $\begin{array}{c}5.014 \\
{[4.302,5.824]}\end{array}$ & $\begin{array}{c}3.911 \\
{[3.326,4.630]}\end{array}$ & $I G(0.75,2.0)$ \\
\hline Std., term premium shock & $\sigma_{\nu(Z)}$ & $\begin{array}{c}5.577 \\
{[4.533,6.861]}\end{array}$ & $\begin{array}{l}5.157 \\
{[4.131,6.432]}\end{array}$ & $I G(1.0,2.0)$ \\
\hline
\end{tabular}

continued on the next page 
Table A1: Estimation Results - continued

\begin{tabular}{|c|c|c|c|c|}
\hline Parameters & & $\begin{array}{c}\text { Posterior } \\
\text { Optimal }\end{array}$ & $\begin{array}{c}\text { Posterior } \\
\text { Rule }\end{array}$ & $\begin{array}{c}\text { Prior dist. } \\
\text { Type (mean,std) }\end{array}$ \\
\hline \multicolumn{5}{|c|}{ Monetary Policy Parameters } \\
\hline inflation term & $\omega_{\pi}^{M}(L)$ & $\begin{array}{c}0.385 \\
{[0.335,0.432]}\end{array}$ & - & $B(0.5,0.15)$ \\
\hline gap term, $\hat{X}_{t}-\hat{\xi}_{t}$ & $\omega_{x}$ & $\begin{array}{c}0.024 \\
{[0.018,0.031]}\end{array}$ & - & $B(0.5,0.15)$ \\
\hline gap term, $\hat{y}_{t}-\frac{\sigma}{\varphi} \hat{\xi}_{t}$ & $\omega_{y}^{M}$ & $\begin{array}{c}0.125 \\
{[0.106,0.149]}\end{array}$ & - & $B(0.5,0.15)$ \\
\hline instrument smoothing term & $\omega_{i}$ & $\begin{array}{c}0.011 \\
{[0.007,0.015]}\end{array}$ & - & $B(0.1,0.05)$ \\
\hline interest rate smoothing & $\rho^{M}(A)$ & - & $\begin{array}{c}0.831 \\
{[0.812,0.849]}\end{array}$ & $B(0.5,0.15)$ \\
\hline interest rate smoothing & $\rho^{M}(P)$ & - & $\begin{array}{c}0.723 \\
{[0.687,0.755]}\end{array}$ & $B(0.5,0.15)$ \\
\hline inflation & $\psi_{\pi}(A)$ & - & $\begin{array}{c}2.631 \\
{[2.467,2.800]}\end{array}$ & $N(2.0,0.25)$ \\
\hline inflation & $\psi_{\pi}(P)$ & - & $\begin{array}{c}0.484 \\
{[0.401,0.571]}\end{array}$ & $N(0.5,0.10)$ \\
\hline output & $\psi_{y}(A)$ & - & $\begin{array}{c}0.679 \\
{[0.571,0.784]}\end{array}$ & $N(0.3,0.10)$ \\
\hline output & $\psi_{y}(P)$ & - & $\begin{array}{c}0.541 \\
{[0.444,0.642]}\end{array}$ & $N(0.3,0.10)$ \\
\hline std policy shock & $\sigma_{M}$ & - & $\begin{array}{c}0.184 \\
{[0.118,0.253]}\end{array}$ & $I G(0.25,2.0)$ \\
\hline \multicolumn{5}{|c|}{ Fiscal Policy Parameters } \\
\hline inflation term & $\omega_{\pi}^{F}(C)$ & $\begin{array}{c}0.778 \\
{[0.614,0.925]}\end{array}$ & - & $B(0.7,0.15)$ \\
\hline inflation term & $\omega_{\pi}^{F}(L)$ & $\begin{array}{c}0.430 \\
{[0.317,0.532]}\end{array}$ & - & $B(0.3,0.15)$ \\
\hline gap term, $\hat{y}_{t}-\frac{\sigma}{\varphi} \hat{\xi}_{t}$ & $\omega_{y}^{F}(C)$ & $\begin{array}{c}0.187 \\
{[0.132,0.238]}\end{array}$ & - & $B(0.5,0.15)$ \\
\hline gap term, $\hat{y}_{t}-\frac{\sigma}{\varphi} \hat{\xi}_{t}$ & $\omega_{y}^{F}(L)$ & $\begin{array}{c}0.471 \\
{[0.374,0.578]}\end{array}$ & - & $B(0.5,0.15)$ \\
\hline gap term, $\hat{X}_{t}-\hat{\xi}_{t}$ & $\omega_{x}$ & $\begin{array}{c}0.024 \\
{[0.018,0.031]}\end{array}$ & - & $B(0.3,0.15)$ \\
\hline instrument smoothing term & $\omega_{\tau}$ & $\begin{array}{c}0.012 \\
{[0.009,0.015]}\end{array}$ & - & $B(0.1,0.05)$ \\
\hline instrument smoothing term & $\rho^{F}(P)$ & - & $\begin{array}{c}0.912 \\
{[0.867,0.950]}\end{array}$ & $B(0.5,0.15)$ \\
\hline instrument smoothing term & $\rho^{F}(A)$ & - & $\begin{array}{c}0.434 \\
0.254,0.587]\end{array}$ & $B(0.5,0.15)$ \\
\hline debt term & $\delta_{b}(P)$ & - & $\begin{array}{c}0.076 \\
{[0.064,0.089]}\end{array}$ & $B(0.05,0.01)$ \\
\hline output term & $\delta_{y}$ & - & $\begin{array}{c}0.366 \\
{[0.323,0.410]}\end{array}$ & $B(0.1,0.025)$ \\
\hline std policy shock & $\sigma_{F}$ & - & $\begin{array}{c}0.343 \\
{[0.304,0.383]}\end{array}$ & $I G(0.25,2.0)$ \\
\hline
\end{tabular}

continued on the next page 
Table A1: Estimation Results - continued

\begin{tabular}{|c|c|c|c|c|}
\hline Parameters & & $\begin{array}{r}\text { Posterior } \\
\text { Optimal }\end{array}$ & $\begin{array}{l}\text { Posterior } \\
\text { Rule }\end{array}$ & $\begin{array}{c}\text { Prior dist. } \\
\text { Type (mean,std) }\end{array}$ \\
\hline \multicolumn{5}{|c|}{ Markov Transition Probabilities } \\
\hline remain in $\mathrm{N}$ regime & $d_{n n}$ & $\begin{array}{c}0.965 \\
{[0.947,0.980]}\end{array}$ & $\begin{array}{c}0.976 \\
{[0.964,0.986]}\end{array}$ & $B(0.1,0.025)$ \\
\hline remain in $\mathrm{Z}$ regime & $d_{z z}$ & $\begin{array}{c}0.050 \\
{[0.028,0.076]}\end{array}$ & $\begin{array}{c}0.059 \\
{[0.037,0.086]}\end{array}$ & $B(0.1,0.025)$ \\
\hline remain in $\mathrm{C}$ or $\mathrm{A}$ monetary regime & $p_{c c}$ or $p_{a a}$ & $\begin{array}{c}0.811 \\
{[0.778,0.844]}\end{array}$ & $\begin{array}{c}0.847 \\
{[0.8783,0.902]}\end{array}$ & $B(0.9,0.05)$ \\
\hline remain in $\mathrm{L}$ or $\mathrm{P}$ monetary regime & $p_{l l}$ or $p_{p p}$ & $\begin{array}{c}0.944 \\
{[0.921,0.966]}\end{array}$ & $\begin{array}{c}0.607 \\
{[0.516,0.692]}\end{array}$ & $B(0.9,0.05)$ \\
\hline $\begin{array}{l}\text { move from } \mathrm{C} \text { or } \mathrm{A} \text { monetary regime } \\
\text { to } \mathrm{Z} \text { regime }\end{array}$ & $p_{c z}$ or $p_{a z}$ & $\begin{array}{c}0.060 \\
{[0.035,0.088]}\end{array}$ & $\begin{array}{c}0.051 \\
{[0.029,0.078]}\end{array}$ & $B(0.05,0.015)$ \\
\hline remain in $\mathrm{L}$ or $\mathrm{P}$ fiscal regime & $q_{l l}$ or $q_{p p}$ & $\begin{array}{c}0.932 \\
{[0908,0.954]}\end{array}$ & $\begin{array}{c}0.873 \\
{[0.784,0.942]}\end{array}$ & $B(0.9,0.05)$ \\
\hline remain in $\mathrm{C}$ or A fiscal regime & $q_{c c}$ or $q_{a a}$ & $\begin{array}{c}0.977 \\
{[0.964,0.987]}\end{array}$ & $\begin{array}{c}0.892 \\
{[0.818,0.948]}\end{array}$ & $B(0.9,0.05)$ \\
\hline remain in $\mathrm{T}$ shock regime & $s_{t t}$ & $\begin{array}{c}0.960 \\
{[0.934,0.980]}\end{array}$ & $\begin{array}{c}0.863 \\
{[0.788,0.926]}\end{array}$ & $B(0.9,0.05)$ \\
\hline remain in $\mathrm{V}$ shock regime & $s_{v v}$ & $\begin{array}{c}0.983 \\
{[0.969,0.994]}\end{array}$ & $\begin{array}{c}0.856 \\
{[0.775,0.924]}\end{array}$ & $B(0.9,0.05)$ \\
\hline $\begin{array}{l}\text { move from } \mathrm{V} \text { shock regime } \\
\text { to } \mathrm{Z} \text { regime }\end{array}$ & $s_{v z}$ & $\begin{array}{c}0.051 \\
{[0.028,0.079]} \\
\end{array}$ & $\begin{array}{c}0.047 \\
{[0.026,0.072]} \\
\end{array}$ & $B(0.05,0.015)$ \\
\hline $\begin{array}{l}\text { Log Marginal Data Densities } \\
\text { and Bayes Factors }\end{array}$ & & $\begin{array}{c}-895.1 \\
(1.00)\end{array}$ & $\begin{array}{l}-1200.5 \\
(4.3 e+132)\end{array}$ & \\
\hline
\end{tabular}

